UNITED STATES

DEPARTMENT OF THE INTERIOR

GEOLOGICAL SURVEY

EVALUATION OF WATER-QUALITY CHARACTERISTICS

OF PART OF THE SPOKANE AQUIFER, WASHINGTON AND IDAHO, USING A SOLUTE-TRANSPORT DIGITAL MODEL

By J. J. Vaccaro and E. L. Bolke

U.S. GEOLOGICAL SURVEY

WATER-RESOURCES INVESTIGATIONS

OPEN-FILE REPORT 82-769

Prepared in cooperation with

the Spokane County Engineer's Office

Tacoma, Washington

1983 


\section{UNITED STATES DEPARTMENT OF THE INTERIOR \\ JAMES G. WATT, Secretary}

GEOLOGICAL SURVEY

Dallas L. Peck, Director

For additional information

write to:

District Chief

U.S. Geological Survey

1201 Pacific Avenue - Suite 600

Tacoma, Washington 98402-4384
Copies of this report can be purchased from:

Open-File Services Section Western Distribution Branch U.S. Geological Survey Box 25425, Federal Center Lakewood, Co lorado 80225 (Telephone: (303) 234-5888) 


\section{CONTENTS}

Page

Abstract-1-

Introduction-...

Scope of work

Acknow ledgments-_.

Description of the study area-

Geologic setting-_.

Extent and thickness of the aquifer-

Ground-water - surface-water hydrology-_...

Hydraulic characteristics of the aquifer

Transmissivity and specific yield

Porosity-_. 8

Discharge and ground-water velocity

Stream-aquifer relationship-_.

Recharge to and discharge from the study area........ 14

Precipitation-_._.

Evapotranspiration-_._._. 16

Ground-water pumpage-_._. 16

Applied water and infiltration-_.

Subsurface flow-_._.

Spokane and Little Spokane Rivers-_._.

Land-use activities-_-_-__n_- 18

Water quality-_.

Areal water-qual ity variations-_.

Vertical water-quality variations

Model construction and calibration-_.

Flow model-_. 42

Mass-transport: mode1-_._- 42

Calibration-........... 43

Calibration of regional dispersivity

Sensitivity analysis-_. 49

Calibration results-a 52

Transient mode! 1-_._. 55

Model utilization-_._. 62

Summary-1, 66

References - . 68 
FIGURE 1. Index map showing location of the study area-................ 5 2-8. Maps showing:

2. Generalized geology of the study area--..............-. 6

3. Saturated thickness of the Spokane aquifer-............. 7

4. Transmissivity of the Spokane aquifer-.................-. 9

5. Specific yield of the Spokane aquifer-................- 10

6. Porosity of the Spokane aquifer-.....................- 11

7. Distribution of ground-water velocity in the study area and gaining and losing reaches of the Spokane and Little Spokane Rivers, as calculated from the time-averaged mode 1

8. Average annual chloride loading to the Spokane aquifer

9. Graph showing relationship between dissolved-solids concentration and specific conductance for ground water in the

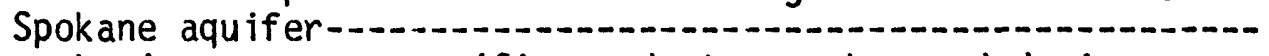

10. Map showing average specific conductance observed during the period May 1977-May 1978, and graphs of specific

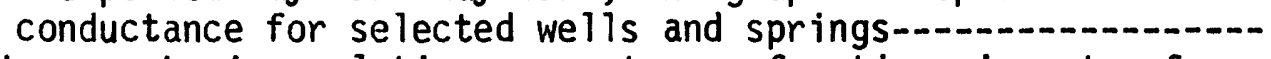

11. Diagram showing relative percentages of cations in water from

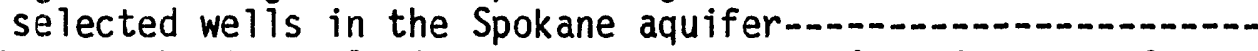

12. Diagram showing relative percentages of anions in water from selected wells in the Spokane aquifer-.......................

13. Map showing distribution of average chloride concentration,

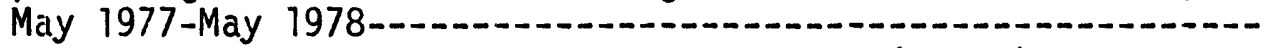

14. Map showing distribution of average nitrate $\left(\mathrm{NO}_{3}-\mathrm{N}\right)$ concentration, May 1977-May 1978-...-...-

15. Map showing location of wells used for vertical sampling--..-16-20. Graphs showing vertical variations in specific conductance, chloride, and nitrate-nitrogen in wells:

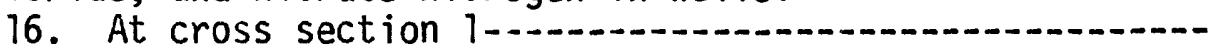

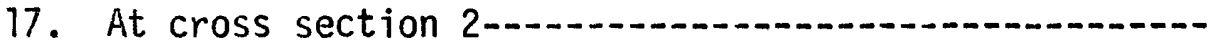

18. At cross section 3-......

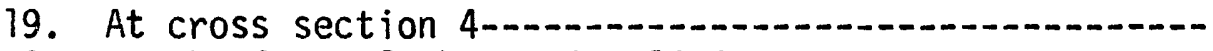

20. North of the Spokane city limits

21. Map showing water-level configuration of the Spokane aquifer, as calculated from the time-averaged model-.................

22. Map showing model-grid network and boundary conditions used

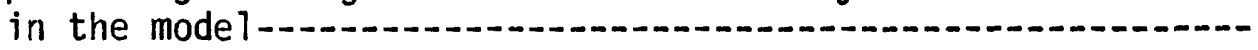

23. Map showing residual chloride concentrations from time-

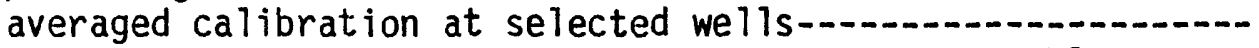

24. Diagram showing the computed temporal variation in chloride

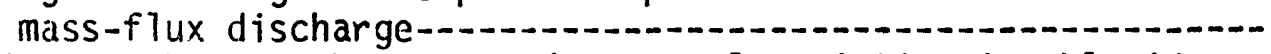

25. Diagram showing the computed temporal variation in chloride

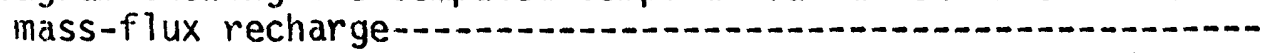

26. Map showing predicted change in chloride concentration due to septic-tank effluent and to irrigation water-.-.-.-.-.-. 


\section{TABLES}

TABLE 1. Water balance for the study area for the period August

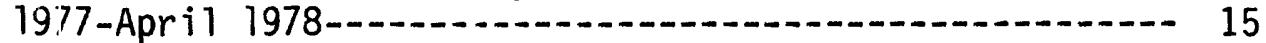

2. Chemical constituents, physical properties, observed ranges, means, and standard deviations-.-.-.-.-.-.-.-.- 23

3. Mean and standard deviation of specific conductance and chloride for the top 10 feet, lower 40 feet, and total thickness penetrated below water table of wells sampled

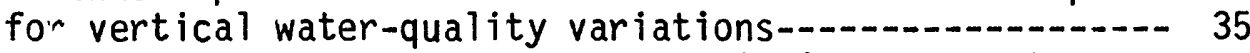

4. Calculated and observed average annual river concentrations at selected river nodes for time-averaged

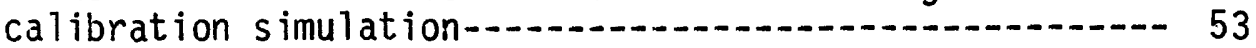

5. Model-calculated chloride mass-flux budget for timeaveraged simulation, May 1972-May 1978-.............-.-.- 54

6. Statistics for transient mass-transport calibration------- 56

7. Calculated and observed chloride concentrations for the

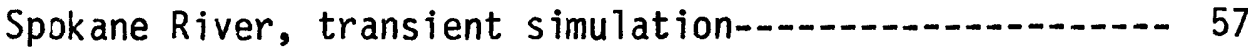

METRIC (SI) CONVERSION FACTORS

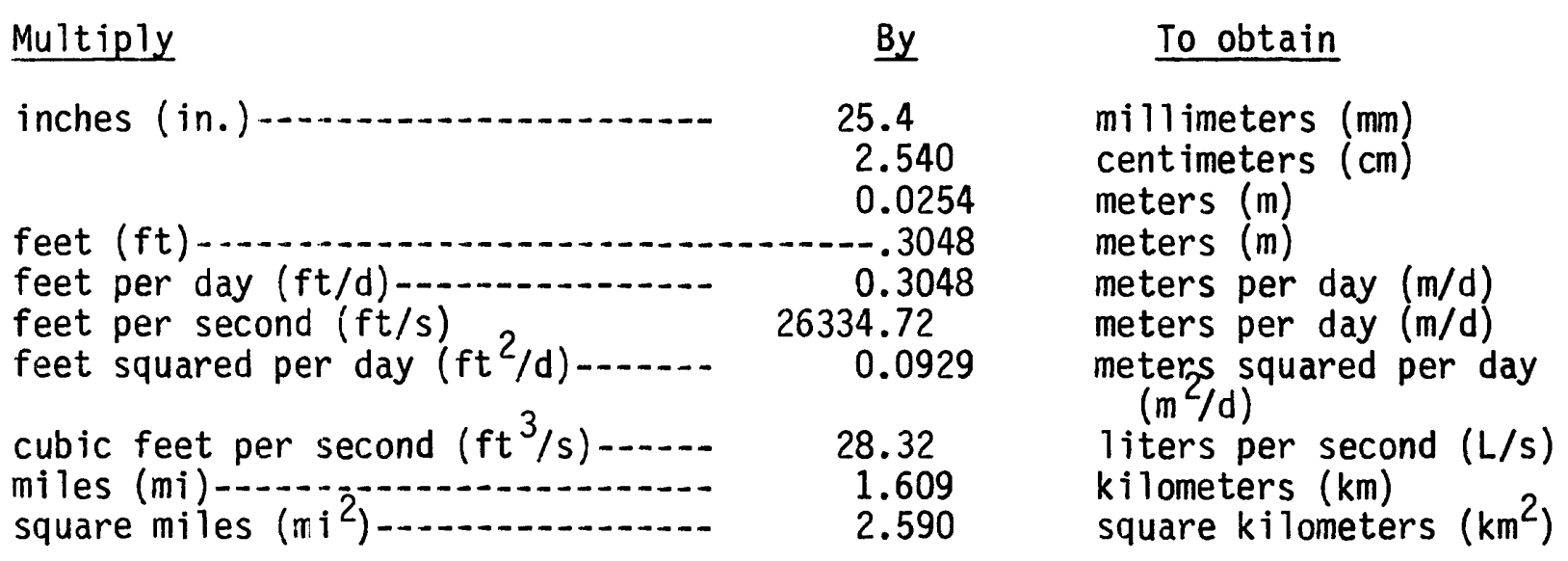

National Geodetic Vertical Datum of 1929 (NGVD of 1929): A geodetic datum derived from a general adjustment of the first-order level nets of both the United States and Canada, formerly called "Mean Sea Level." NGVD of 1929 is referred to as sea level in this report. 


\section{Numbering System for Wells}

Wells in Washington are assigned numbers that identify their location within a township, range, and section. Well number 25/44-17Rl indicates, successively, the township (T.25 N.) and range (R.44 E.), north and east of the Willamette base line and meridian; the letters indicating north and east are omitted. The first number following the hyphen indicates the section (17) within the township, and the letter following the section gives the 40-acre subdivision of the section, as shown below. The number following the letter is the serial number of the well in the 40 -acre subdivision.

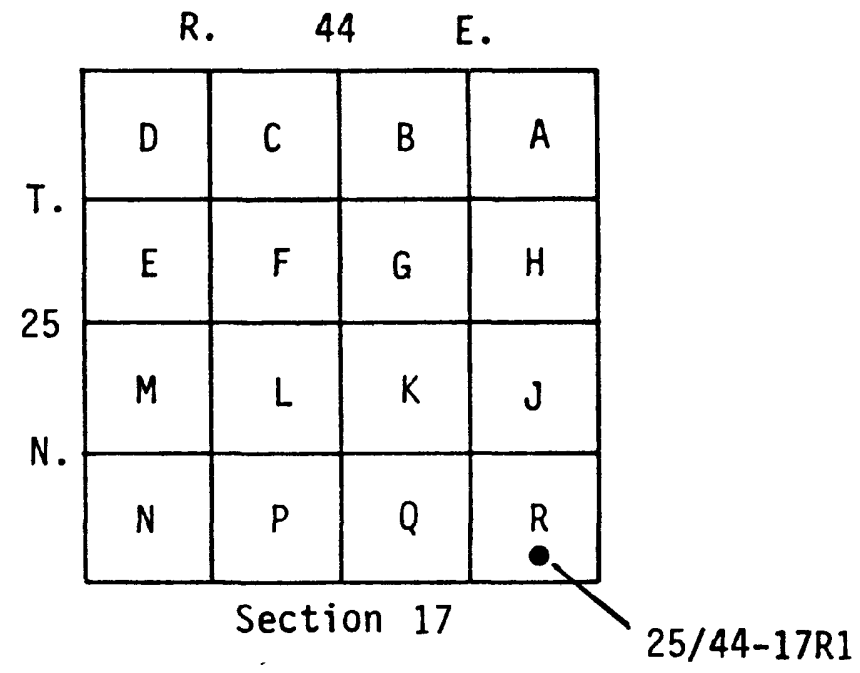




\title{
EVALUATION OF WATER-QUALITY CHARACTERISTICS OF PART \\ OF THE SPOKANE AQUIFER, WASHINGTON AND IDAHO, USING A SOLUTE-TRANSPORT DIGITAL MODEL
}

BY J. J. Vaccaro and E. L. Bolke

\begin{abstract}
The principal dissolved constituents in water in the Spokane aquifer are calcium and bicarbonate. These constituents (as well as dissolved solids, hardness, and magnesium) each correlate well with specific conductance, whereas chloride, sodium, and nitrate each do not. Specific conductance ranges from 73 to 820 micromhos per centimeter throughout the study area. Short-term variations in water quality in the Spokane aquifer are generally greater than long-term variations.

Vertical variations in concentration of chemical constituents occurred in four of 18 wells used to sample the upper 50 feet of the aquifer along several cross sections. Changes in water quality from one cross section to another could not be directly related to land-use activities.

A digital rnodel was developed and used to simulate solute transport of conservative ioris in the Spokane aquifer. Specifically, the model was used to estimate the impact of the chloride ion from recharge through septic tanks and from irrigation on the water quality of the aquifer. Analysis shows that the estimated impact on the aquifer from these two source loadings was less than a 1-milligram-per-liter increase throughout approximately 80 percent of the aquifer, but increases averaging about 3 milligrams per liter occured in some peripheral areas. Various water-quality-management schemes based on manmade or natural stresses can be tested with the model.
\end{abstract}




\section{INTRODUCTION}

The water supply for the city of Spokane, Washington, and the surrounding area is obtained principally from a highly permeable water-table aquifer that underlies the area. The importance of this aquifer as the major source of drinking water was of ficially recognized in 1978, when it was designated as a sole, or principal, source aquifer by the Environmental Protection Agency (EPA) under the provisions set forth in the Safe Drinking Water Act of 1974. Prior to this designation, the Washington State Department of Ecology required information on the water quality of the Spokane aquifer as part of its responsibilities under Public Law 92-500. The Spokane County Engineer's Office was designated by the Washington State Department of Ecology as the lead agency for this effort.

In December 1976, the U.S. Geological Survey, in cooperation with the Spokane County Engineer's Office, undertook a study that would: (1) evaluate the ground-water quality of the Spokane aquifer areally and with depth; (2) determine the nature and guantity of selected chemical constituents entering the aquifer under various land-use categories (urban-suburban/sewered, suburban/nonsewered, agricultural, and industrial); and (3) simulate the movement of selected chemical constituents in the aquifer. Chloride was selected as the chemical constituent to be used in the water-quality modeling effort.

\section{Scope of Work}

In order to describe the water chemistry of the aquifer, water samples were collected by the U.S. Geological Survey from 135 wells distributed throughout the study area (Bolke and Vaccaro, 1979, plate 1). The majority of these wells were large-diameter wells from which water is pumped almost continuously. Data used in the study were obtained from wells sampled in May 1977, October 1977, and May 1978. Eighteen additional wells were drilled and sampled by the Spokane County Engineer's Office to obtain information on water quality in the upper 50 feet of the aquifer.

All the water samples were analyzed for the following constituents or properties: temperature, specific conductance, orthophosphate, chloride, nitrate-nitrogen, nitrite-nitrogen, and ammonia. These characteristics were selected because they are probably representative of the loading from land-use activities in the Spokane Valley. Chemical data that were previously collected by the Geological Survey in a cooperative sampling program with the EPA were also analyzed with the water-quality data collected during the study. 
A land-use map presented in Drost and Seitz (1978) was used to identify areas where chemical loading to the aquifer could be occurring. The major land-use activities resulting in chemical loading to the aquifer were assumed to be industrial and commercial activities, irrigation for agriculture, residential lawn watering in densely populated areas, and septic-tank effluent.

A mass-transport model was constructed to simulate the movement of conservative chemical constituents in the Spokane aquifer, as well as the movement between the aquifer, the Spokane River, and the Little Spokane River. The hydraulic model used in the project was constructed in an earlier study (Bolke and Vaccaro, 1981).

\section{Acknowledgments}

The authors express appreciation to the numerous land owners and water purveyors for their cooperation during the course of this study. Sincere appreciation is also extended to personnel of the Spokane County Engineer's Office for their cooperation. 


\section{DESCRIPTION OF THE STUDY AREA}

The study area is in the Spokane River basin, in eastern Washington and northwestern Idaho (fig. 1), and includes the Spokane River valley from approximately Post Falls, Idaho, on the east to near Nine Mile Falls, Wash., on the west, a distance of approximately 27 miles. The valley ranges in width from about 3 to 8 miles, and covers an area of 135 square miles. The study boundaries north and south of the Spokane River coincide with the contact between the unconsolidated materials that make up the Spokane aquifer and the consolidated rock of the valley sides (fig. 2). A mesa known as Fivemile Prairie, northwest of the city of Spokane, consists of consolidated Tertiary deposits and separates the aquifer into the Hillyard Trough on the east and the lower Spokane River Valley to the southwest. The aquifer is split at a second location by exposed Precambrian rock just north of Opportunity, Wash.

Major tributaries to the Spokane River in the study area are the Little Spokane River and Hangman Creek (fig. 1). Numerous other small tributaries, most of which are ephemeral, also enter the valley.

\section{Geologic Setting}

The generalized geology of the study area was adapted from a geologic map by Griggs (1966). Rocks in the study area were separated into two units (fig. 2) based on their relative permeability. The consolidated Precambrian and Tertiary rocks, composing one unit, are relatively impermeable and allow delineation of the bottom and the sides of the valley. Unconsolidated Quaternary deposits compose the second unit and define the extent and thickness of the valley fill. This unit consists mainly of poorly-sorted, reworked, glaciofluvial deposits of sand and gravel, and is known as the Spokane aquifer.

Unconsolidated deposits, mostly lake sediments and alluvium, make up the valley fill in the small tributary drainages that surround the study area, such as those of Liberty Lake and Newman Lake (fig. 1). Where they are in contact with the glaciofluvial deposits at the valley's mouth, these deposits allow for conveyance of water from the small surrounding drainages to the Spokane aquifer.

\section{Extent and Thickness of the Aquifer}

The glaciofluvial deposits that compose the Spokane aquifer extend throughout the study area, except for an outcrop of Precambrian rock north of Opportunity, Wash., outcrops of Tertiary basalt near Spokane, and Tertiary rocks that compose the mesa at Fivemile Prairie (fig. 2) in Washington. The saturated thickness of these glaciofluvial deposits (fig. 3) ranges from 0 to 500 feet (Bolke and Vaccaro, 1981). Fivemile Prairie and the other areas of consolidated rock mentioned above were included in the map of saturated thickness to simplify the modeling of the system and were delineated by assigning to them a relatively small value of saturated thickness. 


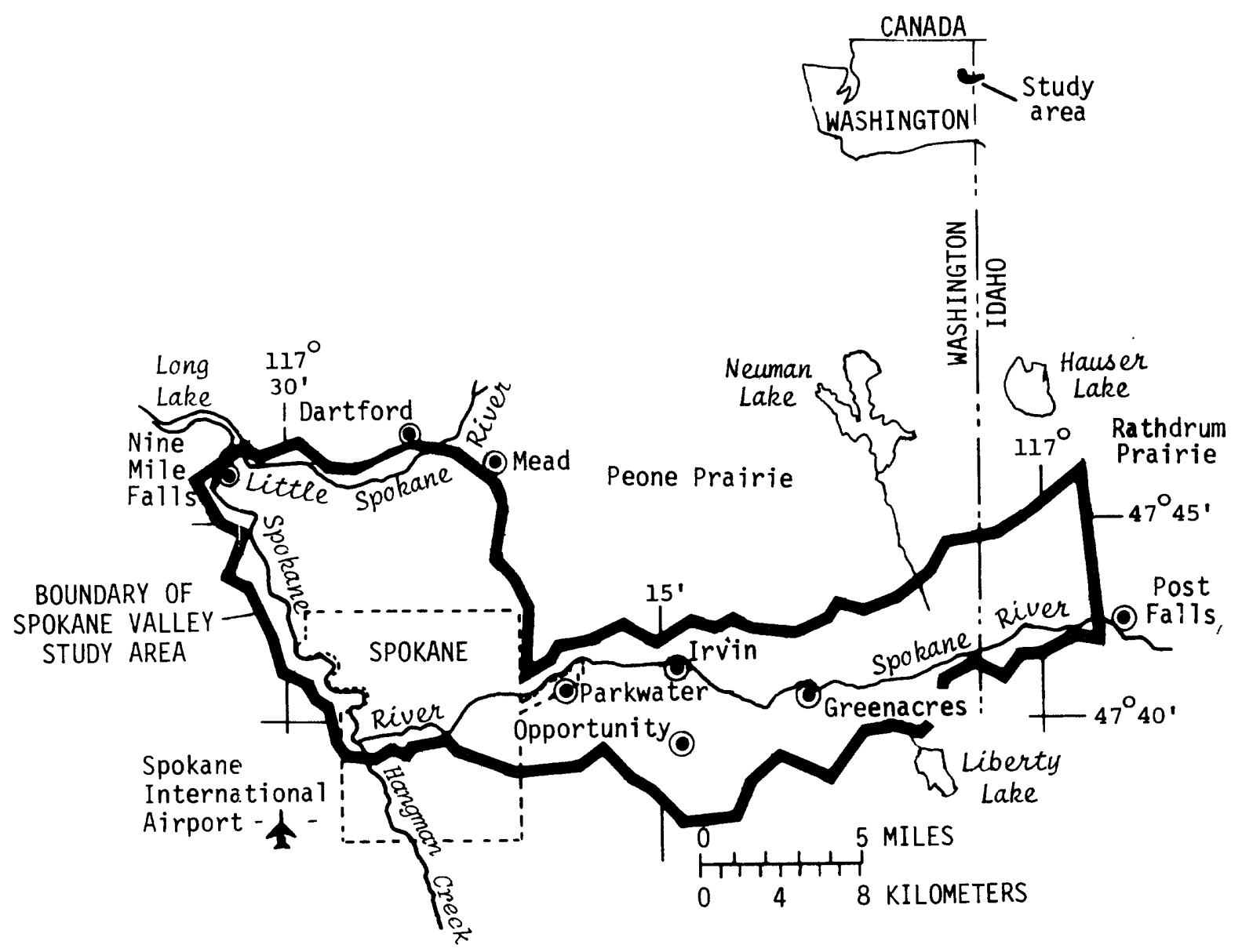

FIGURE 1.--Location of the study area. 


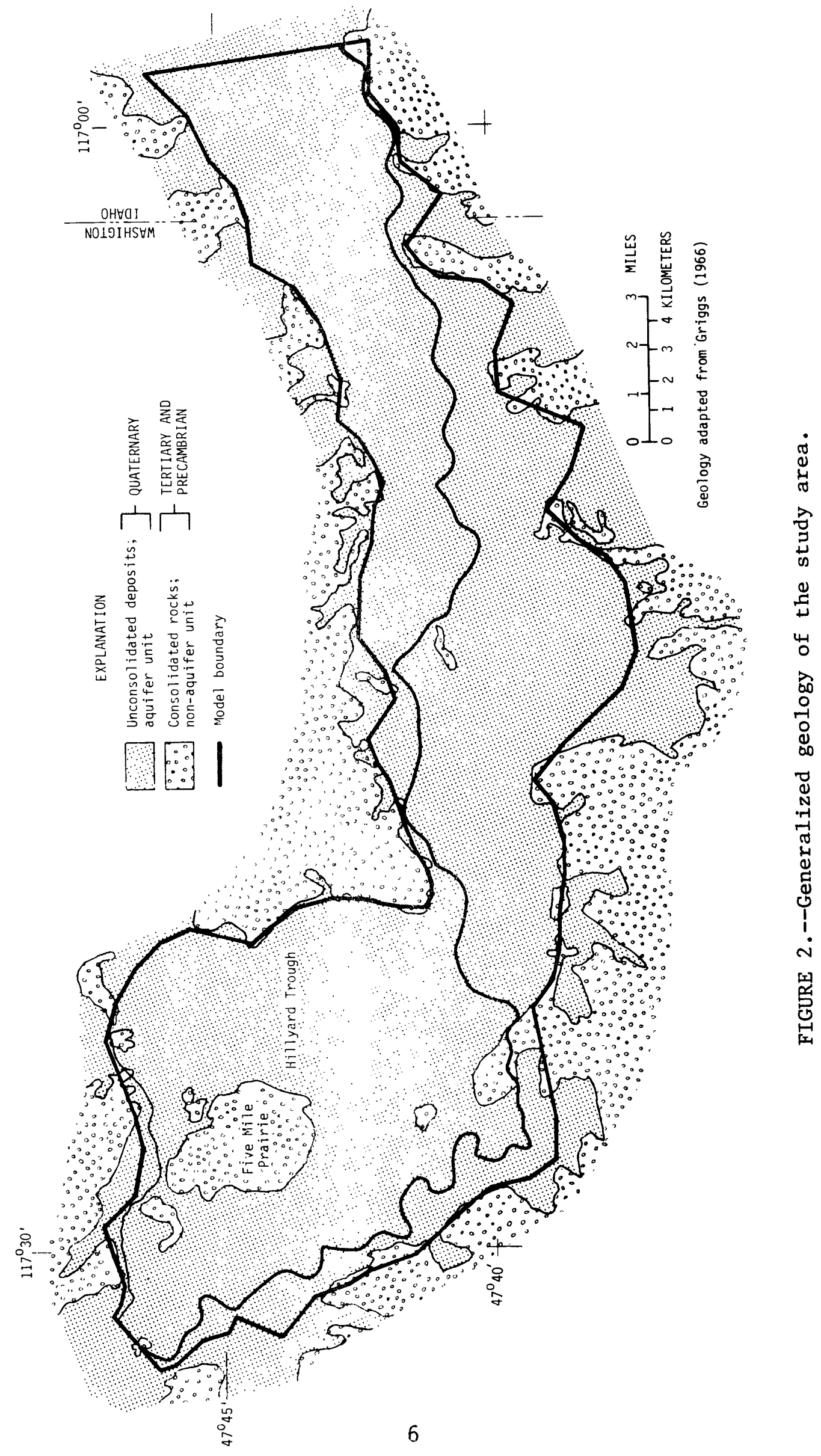




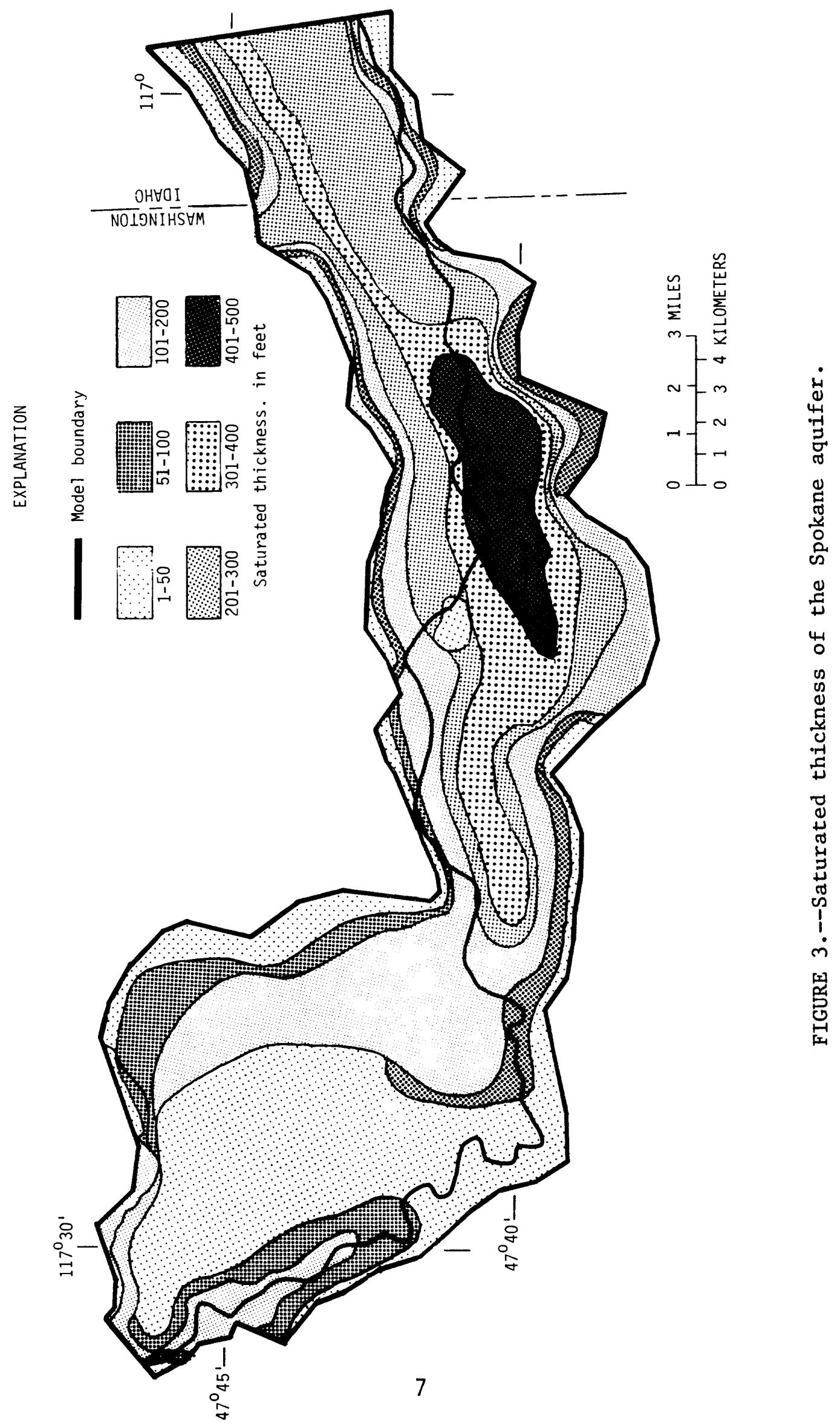




\section{GROUND-WATER - SURFACE-WATER HYDROLOGY}

\section{Hydraulic Characteristics of the Aquifer}

The hydraulic characteristics of the aquifer that are necessary to simulate two-dimensional areal solute transport in the aquifer include transmissivity, specific yield, porosity, dispersivity, discharge per unit width in the aquifer, and the relationship between ground water and surface water in the study area.

\section{Transmissivity and Specific Yield}

The transmissivity of the aquifer, which ranges from 0.001 to 70 feet squared per second, was initially estimated from hydraulic conductivity and saturated-thickness values that were adjusted during calibration of the time-averaged flow model (Bolke and Vaccaro, 1981) to arrive at the transmissivity distribution shown in figure 4. Similarly, the specific yield of the aquifer, which ranges from 0.05 to 0.20 , was initially estimated from lithologic data and then adjusted during calibration of the transient-flow model to arrive at the specific yield shown in figure 5. Details of the calibration process used to refine initial estimates of transmissivity and specific yield were given in Bolke and Vaccaro (1981).

\section{Porosity}

The distribution of porosity, which ranges from 0.07 to 0.40 , was estimated by comparing lithologic information with representative grain size and using tables presented by Johnson (1966). Each distinct vertical zone of aquifer material, obtained from lithologic logs, was assigned a specific yield and porosity value. A thickness-weighted average specific yield and porosity value was then calculated for each log. The specific-yield values, the initial estimates used for the flow model, were then adjusted during the transient-flow model calibration as described in Bolke and Vaccaro (1981).

The calibrated specific yields were then used to estimate the porosity values from tables presented in Johnson (1966). These porosity values were compared with the values obtained from the use of the logs, as previously described. The differences between the site-specific porosity values and the areally averaged values obtained for the calibrated specific yields were small. The distribution of porosity as used in the model is shown in figure 6. 


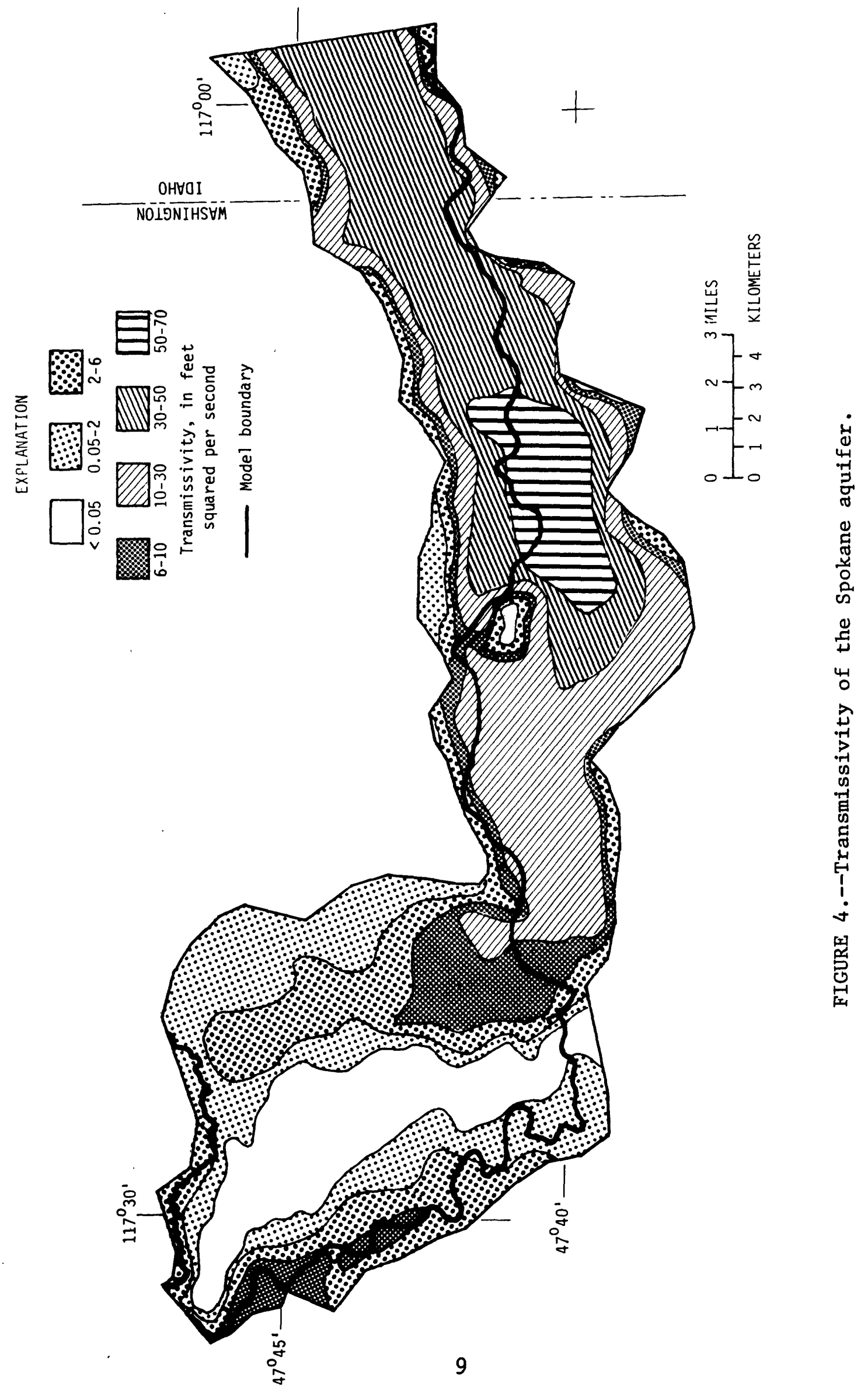




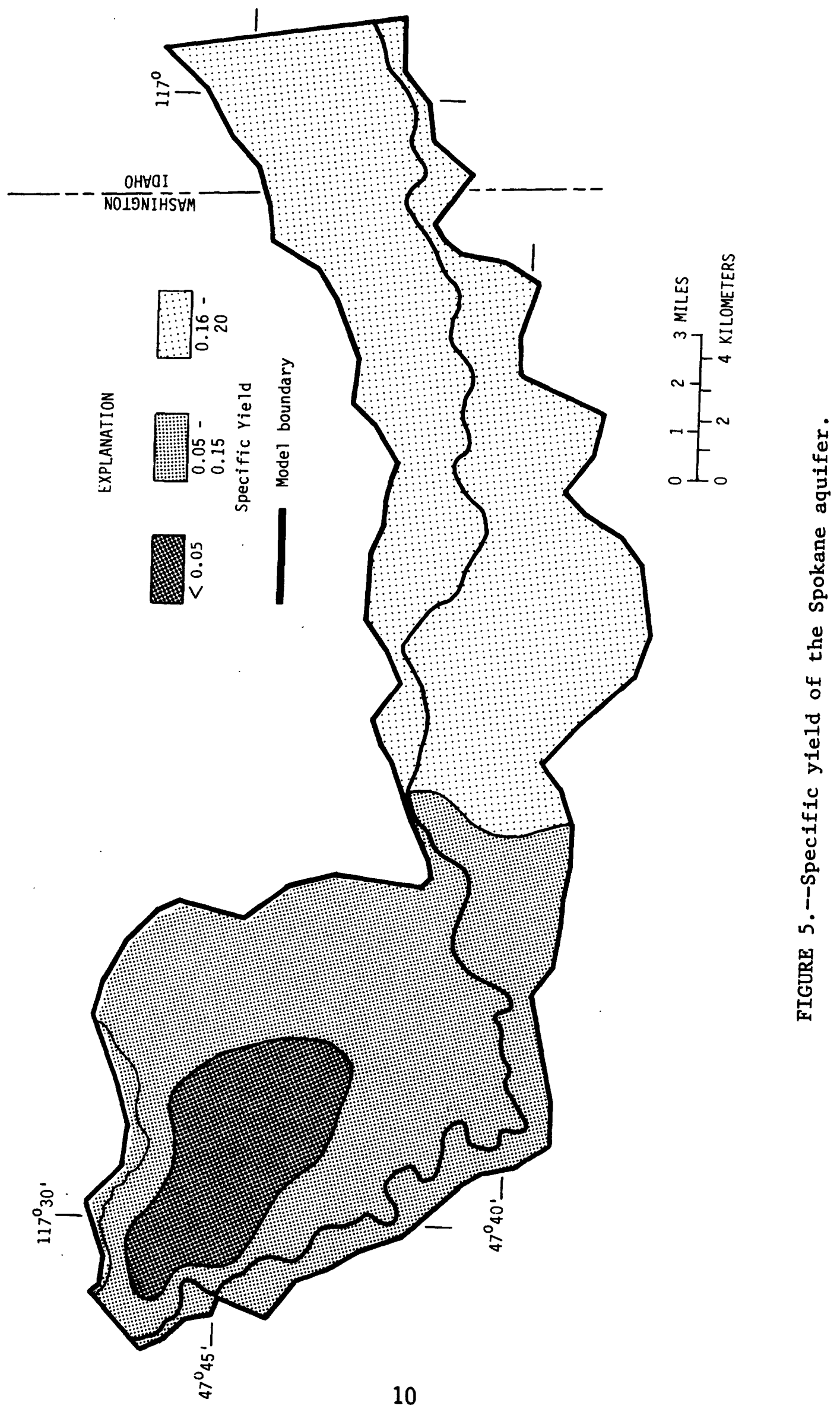




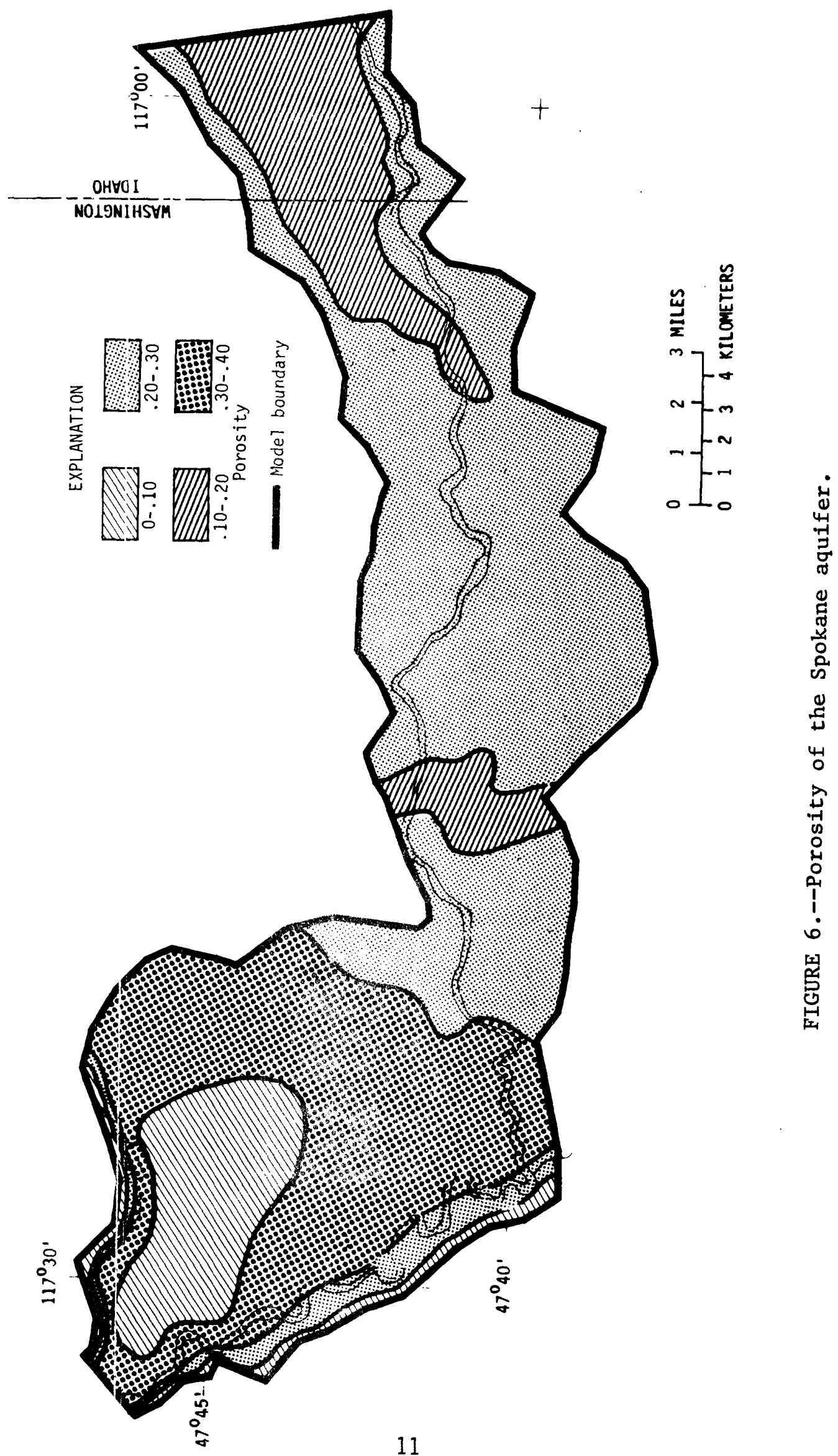




\section{Discharge and Ground-Water Velocity}

The total discharge per unit width (Bear, 1972) represents the flow rate through the saturated thickness of the aquifer per unit width. The parameter was calculated for the Spokane Aquifer using Darcy's law,

$$
q=T \frac{d h}{d l},
$$

where,

$$
\begin{aligned}
\mathrm{q} & =\text { discharge per unit width, } \mathrm{L}^{2} / \mathrm{t} ; \\
\mathrm{T} & =\text { transmissivity, } \mathrm{L} 2 / \mathrm{t} ; \text { and } \\
\frac{\mathrm{dh}}{\mathrm{d} l} & =\text { hydraulic gradient, } \mathrm{L}^{\circ} .
\end{aligned}
$$

The velocity of the ground water, $\mathrm{V}$, was defined using the above relationship and the following equation given by Lohman (1972) and Bear (1972, p. 121),

where,

$$
v=q / \Theta b,
$$

$\mathrm{V}=$ ground-water velocity, $\mathrm{L} / \mathrm{t}$;

$\mathrm{b}=$ saturated thickness, $\mathrm{L} ;$ and

$\mathrm{O}=$ effective porosity, $\mathrm{L}^{\mathrm{O}}$.

The parameters are representative of areally and vertically averaged values and are used to determine $q$ and $V$ in the modeled region. The calculated ground-water velocity, which ranges from 0.01 to $80 \mathrm{ft} / \mathrm{d}$, is shown in figure 7 .

\section{Stream-Aquifer Relationship}

The Spokane River alternately loses water to and gains water from the aquifer throughout the study area. The Little Spokane River gains from the ground-water system in the study area, except near its confluence with the Spokane River, where it may be losing. Hangman Creek discharges into the Spokane River at the boundary of the study area, near the southwest part of the city of Spokane. 


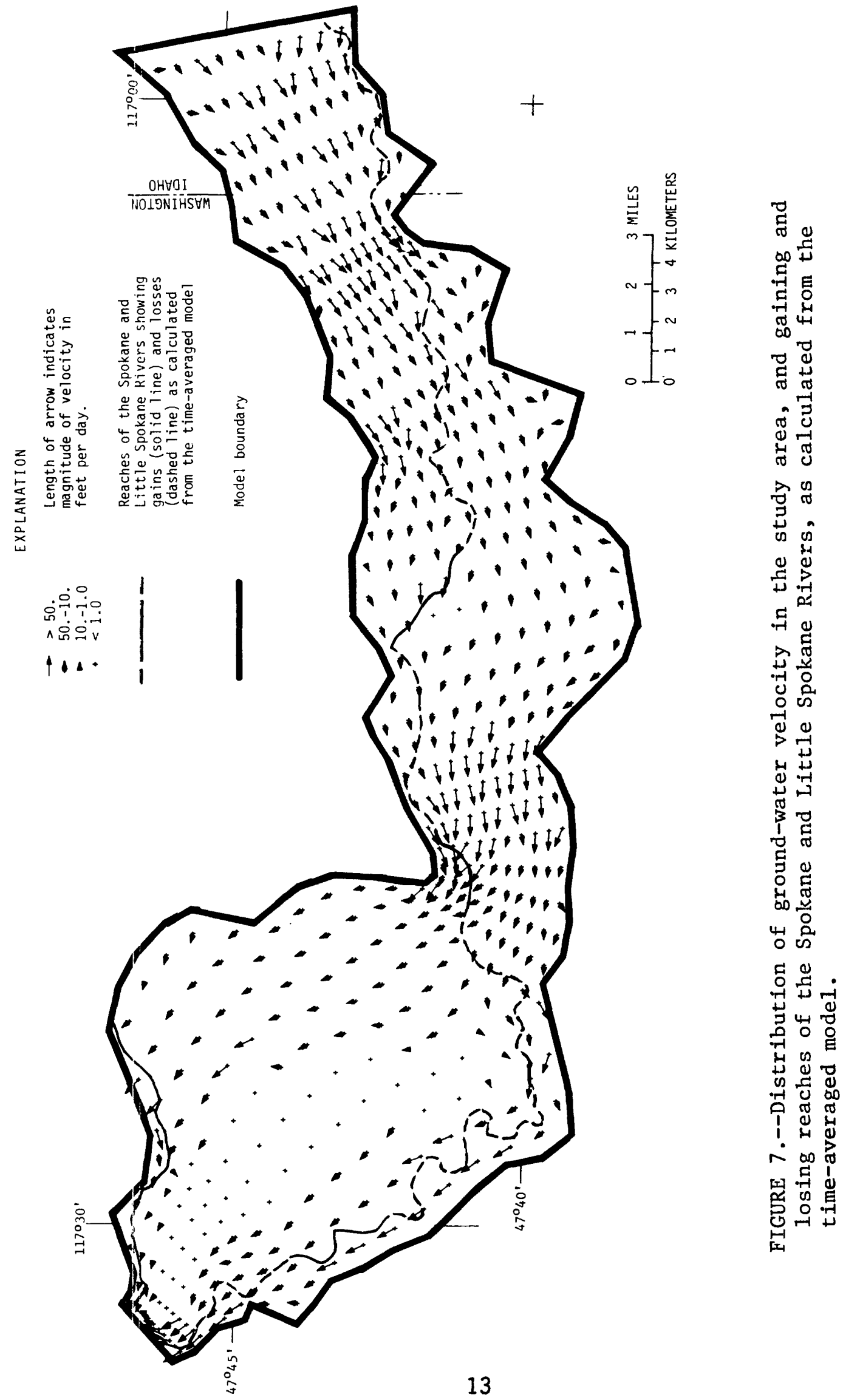


Bolke and Vaccaro (1981) estimated the amount of water moving between the river and the aquifer using the following relationship:

$$
Q=\frac{k_{s}}{m}\left(h_{s}-h_{a}\right) A
$$

where:

$$
\begin{aligned}
Q= & \text { flow rate from stream to aquifer, } \mathrm{L}^{3 / t} ; \\
\mathrm{k}_{\mathrm{s}}= & \text { vertical hydraulic conductivity of the } \\
& \text { streambed, } \mathrm{L} / \mathrm{t} ; \\
\mathrm{m}= & \text { thickness of the streambed, } \mathrm{L} ; \\
\mathrm{h}_{\mathrm{S}}= & \text { elevation of stream surface, } \mathrm{L} ; \\
\mathrm{h}_{\mathrm{a}}= & \text { elevation of aquifer head; or, if } \mathrm{h}_{\mathrm{a}} \text { is } \\
& \text { below the streambed, then the elevation of the } \\
& \text { streambed, } \mathrm{L}, \text { is used; and } \\
\mathrm{A}= & \text { area of streambed, } \mathrm{L} 2
\end{aligned}
$$

The method of analysis and the time-averaged amounts of water calculated for various reaches of the Spokane and Little Spokane Rivers are found in Bolke and Vaccaro (1981, fig. 11). This same relationship is used in the transport model to allow movement of dissolved substances between the river and the aquifer and will be discussed later in this report.

\section{Recharge to and Discharge from the Study Area}

The principal sources of ground-water recharge to the study area are precipitation, return flow from ground water applied to the land surface, recharge from septic tanks (domestic-direct recharge), subsurface flow from the east, north, and south boundaries, and the Spokane River. Water is discharged from the study area by seepage to the Spokane and Little Spokane Rivers, ground-water pumpage, subsurface outflow, and evapotranspiration. Annual average volume rates of recharge and discharge reported in Bolke and Vaccaro (1981) for the study period May 1977 to April 1978 are listed in table 1. The locations and quantities of recharging water and discharging water are needed for the ground-water-flow model and to identify the possible sources, potential causes of concentration increases, and redistribution mechanisms of chemical constituents in the Inass-transport model.

\section{Precipitation}

The average annual long-term precipitation within the boundaries of the study area was estimated to be 17 inches (Bolke and Vaccaro, 1981). During the period in which the aquifer was modeled, May 1977 to April 1978, precipitation was about 21 inches and was assumed to be uniformly distributed in space throughout the study area. The volume rate of precipitation during this period was about $209 \mathrm{ft} 3 / \mathrm{s}$. 
TABLE 1.--Water balance for the study area for the period May 1977-April 1978

Recharge

Precipitation

Subsurface inflow

Land-surface applied water

Domestic direct recharge

$\begin{array}{cr} & \left(\mathrm{ft}^{3} / \mathrm{s}\right) \\ & 209 \\ & 668 \\ & 114 \\ & 20 \\ \text { Total } \quad 1,011\end{array}$

Discharge

Leakage to Spokane River

282

Leakage to Little Spokane River

254

Ground-water pumpage

227

Subsurface outflow

105

Evapotranspiration

Total 


\section{Evapotranspiration}

Water lost from the study area by evapotranspiration is limited to the moisture lost from open-water surfaces and from the root zone. The depth to the water table in nearly all parts of the area is too great, generally greater than $60 \mathrm{feet}$, to allow for transpiration by plants from the ground-water reservoir. Transpiration by plants from the ground-water reservoir occurs locally near the Spokane and Little Spokane Rivers, and evaporation occurs from the water surface of the rivers and surface-water reservoirs in the area, but these amounts are negligible. Water available for evapotranspiration is derived from precipitation and from water applied to the land surface. The calculated volume rate of evapotranspiration (Bolke and Vaccaro, 1981) during the study period was about $143 \mathrm{ft}^{3} / \mathrm{s}$.

\section{Ground-Water Pumpage}

Based on an inventory of all the major water purveyors, the rate of water pumped from wells in the study area during 1977 was about $227 \mathrm{ft} / \mathrm{s}$, compared with $178 \mathrm{ft}^{3} / \mathrm{s}$ in 1972 and $100 \mathrm{ft}^{3} / \mathrm{s}$ in 1938.

The major wells pumping from the aquifer that were incorporated in this study were analyzed by placing each well into one or several of the following well-type categories (with the pumpage rate separated accordingly): City of Spokane main wells, City of Spokane peak-demand wells, domestic wells, irrigation wells, and industrial wells. The principal uses of ground-water pumpage from these well-type categories are municipal, irrigation, and industrial. Municipal use is mostly for domestic and commercial purposes, but also includes some water that is used for irrigation and industry. The other major categories, irrigation and industry, also include lesser amounts of water that are used for domestic purposes. In 1977, water used for municipal purposes was about 70 percent of the total pumpage, or 116,000 acre-feet. Uses of water for irrigation and industry were each about 15 percent of the total, or 24,000 acre-feet each.

\section{Applied Water and Infiltration}

Water pumped from the aquifer is applied to the land surface as part of irrigation, industrial, or domestic practices, discharged to sewer systems, or assumed to return to the aquifer by infiltration from septic systems. Based on the average monthly pumping rate for a particular well type, the percentage of pumped water that went to lawn watering and irrigation (land-surface-applied water affected by evapotranspiration), septic tanks, consumptive loss, and sewer systems was determined. As an example, suppose a municipal well pumps at an average annual rate of $10 \mathrm{ft}^{3} / \mathrm{s}$ and this annual rate has a cyclic variation in a year. The well purveyors' records indicate that of the pumped water, 70 percent goes to individual homes and the remainder goes to a farm for agricultural use. Therefore, $7 \mathrm{ft} / 3$ is listed as a domestic well type and $3 \mathrm{ft}^{3} / \mathrm{s}$ is listed as an irrigation well. It was found that this annual rate varies on a monthly basis for each land-type use and this variation can be accounted for by multiplying the annual rate by a monthly 
factor estimated from the purveyors' records. Also, from this monthly change is evident that the quantity pumped in the winter months is the minimum, and that the variation above this rate is accounted for by increased usage for lawn and irrigation watering-in other words, the percentage of the pumped water that is applied to the land surface. Therefore, for the domestic use, a percentage of the pumped water goes to septic tanks and the rest goes to lawn watering. (The water that goes to lawn watering is put in a "pool" together with precipitation and irrigation water in the same distribution area; this quantity is affected by evapotranspiration.) If $4 \mathrm{ft}^{3} / \mathrm{s}$ (obtained from multiplying $7 \mathrm{ft}^{3} / \mathrm{s}$ by a monthly factor) is pumped in January, all the water goes to the septic systems for direct recharge and no water is applied to the land surface; in August, $9 \mathrm{ft}^{3} / \mathrm{s} \mathrm{might} \mathrm{be}$ pumped, and a percentage of this water is applied to the land surface and is put into the "pool." Similarly, for the annual rate of $3 \mathrm{ft}^{3} / \mathrm{s}$ for irrigation use no water is pumped in January, but $6 \mathrm{ft}^{3} / \mathrm{s}$ is pumped in August, and of this amount, 100 percent is applied water.

The amount of water applied to the land surface from pumping of Spokane city wells for municipal use was estimated to be 50 percent of the total pumpage ( 88 $\left.\mathrm{ft}^{3} / \mathrm{s}\right)$. The residual was discharged to the sewer system. Of the total amount of water pumped from wells of other municipalities, 70 percent was applied to the land surface and 30 percent was assumed to return to the aquifer by infiltration from septic systems. One hundred percent of the water pumped from irrigation wells was applied to the land surface. About 5 to 10 percent of the water pumped by industry was applied to the land surface, and the rest was either discharged to sewer systems or assumed to return to the aquifer by infiltration from septic systems. The volume rate of water applied to the land surface during the 1-year period May 1977-April 1978 was estimated to be $114 \mathrm{ft} / \mathrm{s}$, and the amount of water estimated to return to the aquifer by infiltration from septic systems was about 20 $\mathrm{ft}^{3} / \mathrm{s}$. These two quantities differ slightly from those given in Bolke and Vaccaro (1981) because of an update of the available water purveyors' records.

\section{Subsurface Flow}

Water recharges the Spokane aquifer by subsurface inflow along the east, north, and south boundaries of the study area. The subsurface flow along the east boundary is a continuation of subsurface inflow from the Rathdrum Prairie aquifer in Idaho and was calculated from the time-averaged flow model to be $399 \mathrm{ft}^{3} / \mathrm{s}$ for the study period. Subsurface inflow along the north and south boundaries enters the area from small drainage basins, such as Newman Lake and Liberty Lake, where the water-bearing material is in contact with the Spokane aquifer. The estimated volume rate of recharge from the north and south boundaries was $269 \mathrm{ft}^{3} / \mathrm{s}$, from work by Thomas (written commun., 1963). Combining this with subsurface inflow from Idaho gives $668 \mathrm{ft}^{3} / \mathrm{s}$ as subsurface inflow to the study area.

Water leaves the study area as subsurface outflow along a part of the western boundary. The total subsurface outflow from the study area was calculated from the time-averaged flow model to be $105 \mathrm{ft} 3 / \mathrm{s}$. 
Spokane and Little Spokane Rivers

The hydraulic connection between the aquifer and the Spokane and Little Spokane Rivers, described earlier on page 12, allows water to move from the aquifer to the rivers and vice versa.

The Spokane River alternately loses water to and gains water from the aquifer as it flows through the study area, and the Little Spokane River gains through its entire reach of the study area except near the confluence with the Spokane River, where it may be losing water to the aquifer. The various reaches of the two rivers where, after time-averaging, water is lost to or gained from the aquifer are shown in figure 7. The net gain of the Spokane River at the western boundary of the study area was calculated from the flow model to be about $282 \mathrm{ft} 3 / \mathrm{s}$, and the gain of the Little Spokane River at the western boundary was calculated to be about $254 \mathrm{ft} / \mathrm{s}$.

\section{Land-Use Activities}

More than one-quarter of a million people live and work in the Spokane area. Water for their domestic, industrial, and agricultural needs is obtained principally from the Spokane aquifer. After water is pumped from the aquifer and utilized, it is returned to the ground-water system minus the amount consumed. Major avenues of return are assumed to be municipal sewage discharges to the Spokane River, numerous residential septic systems, industrial discharges, and infiltration from irrigation.

In general, agricultural activities predominate between the Washington-Idaho state line and the community of Greenacres (fig. 1). Localized agricultural areas also exist north and south of Opportunity. In this reach, agricultural land use has been decreasing as urban and residential development increase. Concurrent with this land-use change is a similar change in the use of and demand for ground water.

West of the community of Greenacres, in a strip through the central part of the valley and into and through the city of Spokane, commercial and light industrial activities predominate, with urban development on the perimeter. Just to the northwest of Greenacres are industrial facilities. The Opportunity area and the area to the south are heavily developed residential areas with individual septic systems.

Within the city limits of Spokane (fig. 1), residential and commercial activities surround the previously mentioned narrow east-west strip of commercial and light industrial use. Because the city is sewered, the return of water from most city activities is through the central sewage system. Water used for landscaping and other outdoor activities is subject to evaporation or eventual percolation through the unsaturated zone to the zone of saturation. Northwest of the city limits, the land is used for generally commercial and residential and some agricultural purposes. 
To support these activities, water is pumped from the aquifer and distributed to some point of delivery. The distributed water returns to the aquifer as either domestic-direct recharge or land-surface-applied recharge (after evapotranspiration), generally at some point other than where it originated. These activities can have a deteriorating effect on water quality through the addition and(or) concentration of material dissolved in the water.

Recharge to the aquifer from a particular land-use activity can be assessed in several ways. The approach used in this study was to assign water use and degradation concentrations to the various land-use activities, based on the distribution records of the water purveyors of the area and the activity utilizing the water. Water pumped by the major wells in the study area was assigned a water-use activity by putting it into a particular well-type category, as discussed previously in the ground-water-pumpage section. Each water-use type from each well was then distributed as previously described in the applied-water section. The concentration of the land-surface-applied water was assumed to be approximately equal to the concentration of the native ground-water (the pumped water). The other water-use types, industrial and septic-tank effluents, were assigned an estimated chloride concentration obtained from published literature. These estimated concentrations were greater than the aquifer concentration and therefore are degradation concentrations. The separation of pumpage into water-use types and the distribution of the pumped water to various locations over the aquifer are incorporated into the mass-transport model to determine aquifer loading (mass-flux recharge) and to evaluate the impact of the loading.

The results of using this approach to assess recharge to the Spokane aquifer from a particular land-use activity are seen in figure 8, which shows the relative amount of chloride entering the aquifer from the major land-use activities. The average annual chloride loadings, as shown in figure 8, tabulated in table 7, and discussed later in the section Areal Water-Quality Variations, p. 22, are used in conjunction with the mass-transport model to assess the impact of the most important land-use activities.

The largest chloride loadings occur south of Opportunity, near Mead, and north of Irvin (figs. 1 and 8). The loadings south of Opportunity are due to the effects of dense residential development, and the loadings in the peripheral area near Irvin are due to the effects of both residential and industrial development. In general, the loading map can also be thought of as a population-density map in the residential areas:--the greater the population, the greater the estimated loading to the ground-water system. Even in the part of Spokane that is sewered, a theoretical loading exists because of land-surface-applied recharge. Agricultural land use in the eastern parts of the valley contributes only limited chloride loading to the Spokane aquifer. The loading map does not imply cause-effect relationships, but only where aquifer loading does occur. The impact of land-use loading is discussed in sections Model Utilization and Water Quality of this report. 


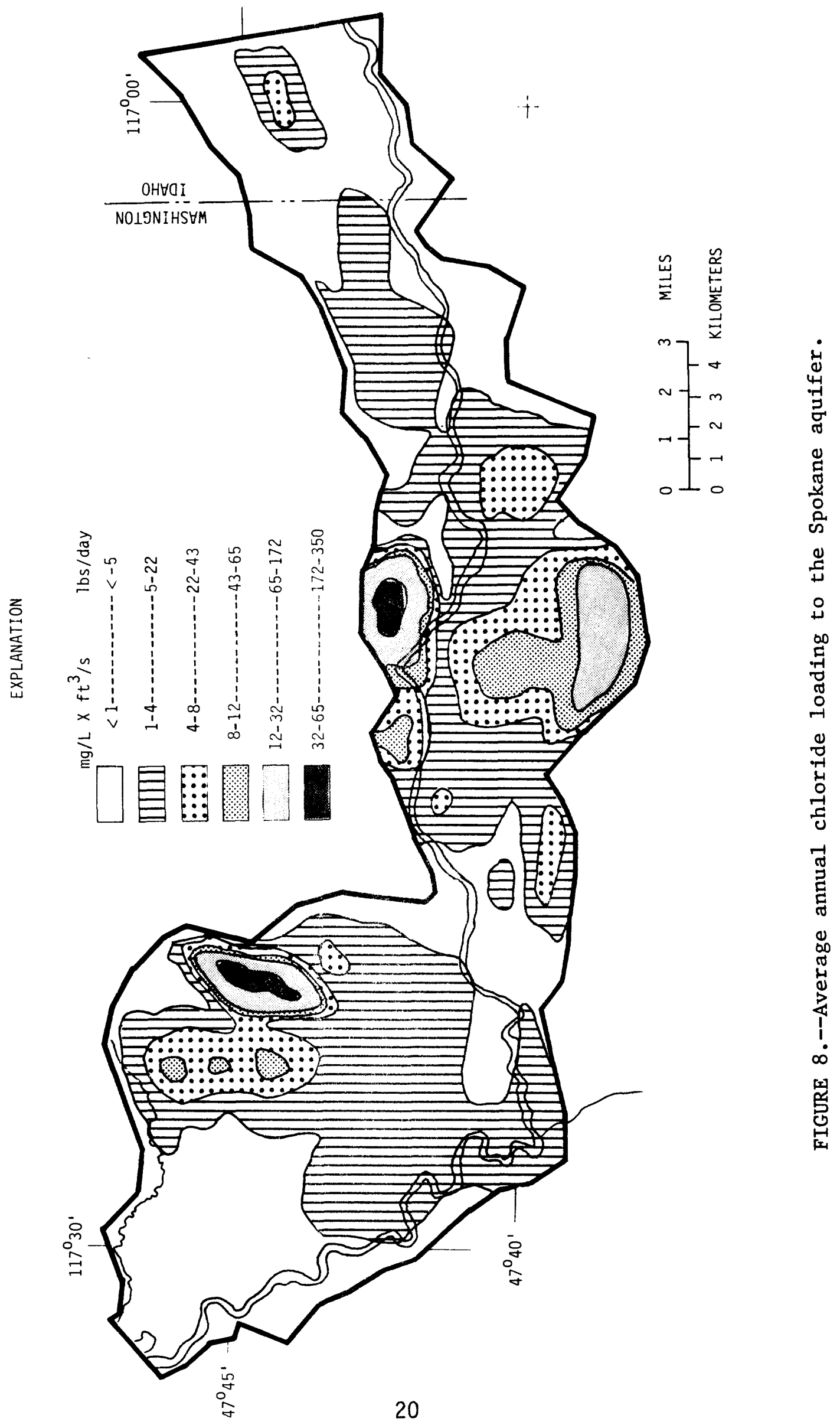




\section{WATER QUALITY}

An objective of this study was to assess areal and vertical water-quality variations in the Spokane aquifer. Areal assessment was achieved by sampling 135 wells three times during the study (May 1977, October 1977, and May 1978), and vertical assessment was achieved by sampling 17 wells at five depth intervals in October 1977 and May 1978 and at six depth intervals in May 1977. The results of the water-quality sampling are contained in Bolke and Vaccaro (1980).

The chemical quality of ground water in the Spokane aquifer at any given sampling point may vary in response to recharge from land-use activities, recharge from the river, changes in the rate of water movement, or the direction of movement or pumping. Separating the effects of natural and man-induced factors on water quality is of ten complex, especially when considering constituents of low concentration in dynamic systems such as the Spokane aquifer. The assessment included examining the concentrations of the constituents sampled, comparing the present water-quality standards with the sample concentrations, and analyzing the observed areal and temporal variations.

A comprehensive assessment of water quality in terms of suitability for all intended uses was not an objective of this study. Therefore, water samples were analyzed for those chemical constituents that could be used to assess variations in water quality that might indicate recharge from a particular land use. Large-capacity wells that were pumping prior to sampling were preferred as sampling sites. However, as an adequate areal coverage was needed, it was necessary to use partially penetrating wells that pump at a low rate and(or) had not been pumping for a long time prior to sampling. It has been shown by Mundorff and others (1972) that partially penetrating wells still deliver water from the entire saturated thickness of the aquifer. Though the samples are obtained from the entire thickness, the quantity of aquifer water from different depths will, in general, not be equal. Thus, the sample will generally be a weighted representative vertically integrated sample, with the weighting to the upper depths. This sample will typlify the result of an integration of numerous events that may dilute or add dissolved material to water. In general, the chemistry of a water sample may be attributed to all previous land-use activities to which that water has been exposed, as well as to natural chemical reactions. Due to these natural and man-induced factors and to the quality of water in the aquifer, the quality of water from a well generally fluctuates slowly with time.

A shallow-ground-water-monitoring program was instituted because of the absence of a program designed to sample and monitor water percolating through the unsaturated zone. Eighteen wells were drilled to depths of approximately 50 feet below the water level by the Spokane County Engineer's Office along several selected cross sections. The cross sections were selected to represent gross changes in land-use activities and to provide data to assess vertical variations at specific sites. Water samples were obtained from five or six depths in most of these wells in May 1977, October 1977, and May 1978. The casings of these wells were perforated from a short distance above the water table to the bottom of the hole. Samples were obtained by lowering a submersible pump to the desired depth, sealing the 6-inch casing above and below the pump with inflatable packers, and pumping for a time sufficient to clear the pipe casing and establish flow into the 
packed off location before sample collection. Changes in water quality between the cross sections were then evaluated on the basis that they might result from activities upgradient from each cross section.

The method of water-sample collection to define vertical variation was not ideal because some mixing of water in the well casing was inherent in the sampling process. As a result of this mixing, the observed vertical variations or differences are probably less than those that actually exist. When the data from cross-sectional wells for the upgradient land uses are examined, the following effects should be considered: 1) proximity to parts of the aquifer that are hydraulically connected to reaches of the Spokane River; 2) proximity to aquifer boundaries; and 3) variations in aquifer characteristics.

\section{Areal Water-Quality Variations}

The following discussion presents the results of areal sampling, possible cause-effects relationships, and a reference to the water-quality standards (EPA, 1976). For those constituents sampled during the study period, a tabulation of the mean, standard deviation, and minimum and maximum value is presented in table 2.

Dissolved solids (DS), as defined by the U.S. Geological Survey, is the sum of all the major constituent concentrations measured in a rather complete chemical analysis of a water sample that has been filtered through a 0.45 -micrometer pore-size membrane filter. Often, however, the water-quality recommended limit may be specified in terms of total dissolved solids (TDS). TDS is measured directly by evaporating a filtered water sample to dryness and weighing the residue. Usually, DS and TDS are basically the same, except in waters of unusual composition. The recommended limit for TDS in a domestic water supply, 500 $\mathrm{mg} / \mathrm{L}$, is generally not exceeded in the ground water of the Spokane Valley.

Often, in the absence of dissolved-solids data, specific conductance (the ability of a water to conduct an electrical current) can be used to accurately estimate a value of DS. If an adequate relationship between dissolved solids and specific conductance can be estimated from available data, then this relationship and specific conductance data can be used alone. The relationship between DS and specific conductance for ground water from the Spokane aquifer is shown in figure 9, and was obtained from data collected by the Geological Survey in a cooperative sampling program with the EPA. Specific conductance values from the May 1977-May 1978 sampling period ranged from 73 to 820 micromhos per centimeter at $25^{\circ} \mathrm{C}$ (hereafter called micromhos), with a mean of 307 micromhos. The majority of the observed values were less than 600 micromhos, and about 80 percent of the observed values were in the 200 to 400 micromhos range. In general, this relationship holds for the range of specific-conductance values encountered in the Spokane Valley, with exception of those areas that may be affected by point sources such as sewage disposal, land fills, or industrial spills. Point sources generally contribute a unique water type and, although a dissolved-solids conductivity relationship exists for that input concentration and composition, it will not be the same as the relationship established for the entire valley. 
TABLE 2.--Chemical constituents, physical properties, observed ranges, means, and standard deviations. 1 (Number of samples is 373 )

\begin{tabular}{lcccc}
\hline CONSTITUENT & MINIMUM & MAXIMUM & MEAN & $\begin{array}{c}\text { STANDARD } \\
\text { DEVIATION }\end{array}$ \\
\hline Nitrate - N & 0.00 & 8.8 & 1.77 & 1.46 \\
Nitrite - N & .00 & .01 & .003 & .002 \\
Ammonium - N & .00 & .8 & .045 & .105 \\
Orthophosphate & .00 & .13 & .01 & .022 \\
Chloride & .4 & 24. & 4.00 & 4.2 \\
Temperature (OC) & 6.4 & 21.1 & 11.0 & 1.54 \\
Specific conductance & 73. & 820. & 307. & 106. \\
\hline
\end{tabular}

1 Values are concentration in milligrams per liter (mg/L) except specific conductance, which is reported as micromhos per cent imeter at $25^{\circ} \mathrm{C}$. 


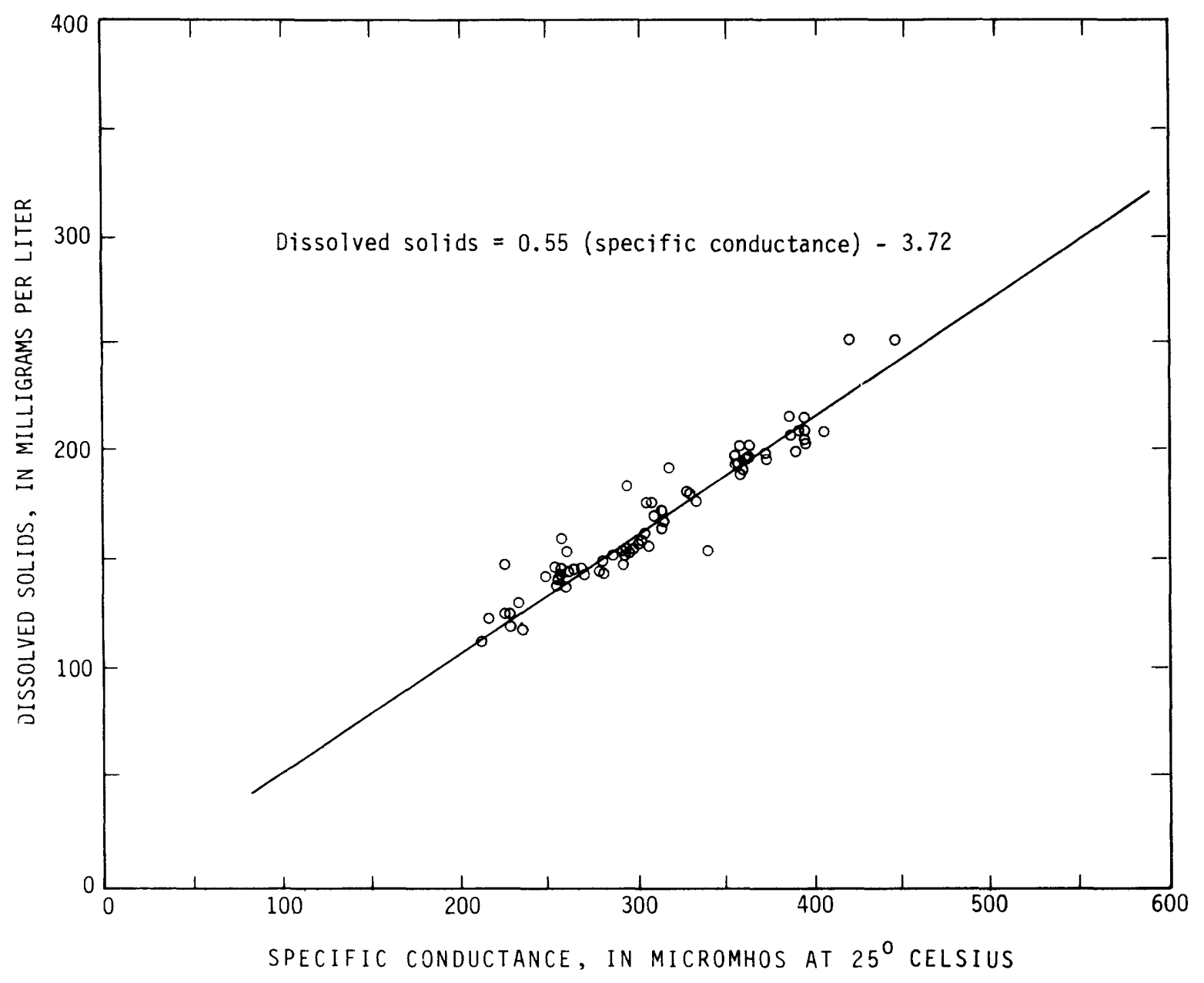

FIGURE 9.--Relationship between dissolved-solids concentration and specific conductance for ground water in the Spokane aquifer. 
The areal variation in specific conductance is shown in figure 10. This plot represents an average for the three sampling events during the study - May 1977, October 1977, and May 1978. In most places, small variations occurred between the observations at various time periods. Specific-conductance values are lowest (the observed values were less than 100 micromhos) in the extreme southeast part of the valley, where the river is losing water, and along the Spokane River, where the central portion of the aquifer contains water with a specific conductance of between 200 and 300 micromhos (dissolved solids range from 100 to $150 \mathrm{mg} / \mathrm{L}$ ). Higher specific-conductance values are observed at the valley perimeters, as shown in figure 10. As this water flows downgradient, it is mixed with and diluted by the water in the central portion of the aquifer. The highest specific conductance values (greater than 500) are observed in the peripheral area around Mead in the northern part of the study area, just south of the Little Spokane River, and in the peripheral area south of Opportunity. The average specific conductance of water entering the upstream (eastern) model boundary is about 290 micromhos. Wells that are directly influenced by river leakage exhibit lower specific conductance; for example, well $25 / 45-9 \mathrm{Bl}$, figure 10 , which is very close to a losing reach of the river, has an average conductance value of about 140 micromhos. Downstream, north of the city limits of Spokane, the specific conductance is about the same as the ground water: entering the upstream-eastern boundary; for example, wells 26/43-7P1, 26/43-17JI, and 26/43-20D1 have average specific-conductance values of about 308, 308, and 259 micromhos, respectively. Little change is observed in the specific conductance of ground water in the central part of the valley as it flows downgradient and is subjected to input from all the various land uses previously discussed. In general, specific conductance ranges from 200 to 300 micromhos and is closely controlled by the velocity field of the ground-water system and the degree of interchange with the river. Local increases are documented and can be attributed to land-use activities (fig. 8) and boundary inflows. This aspect is discussed later in the Sensitivity Analysis and Model Utilization sections.

Historical trends in specific conductance are shown in figure 10 for several wells. Most of the data are from wells and springs sampled and analyzed by the Geological Survey in an effort, with EPA, to monitor the water quality of the aquifer. These trends indicate the reasonableness of the averagespecific-conductance map and show the variations to be mainly short-term (seasonal) and generally exceeding the magnitude of the long-term variation, as indicated by the data from well 25/42-13Bl. The seasonal fluctuations result from the influence of the river and boundary inflow. Most of the ground water flowing westward south of Five-Mile Prairie is estimated to flow through the area represented by this well.

Drost and Seitz (1978, p. 39) analyzed data for 10 ground-water sites with the most complete, long-term water-quality records available. They concluded that the concentration of any one constituent at any particular site is subject to significant random variation from one sampling date to the next, and, therefore, no long-term trends of changing water quality were readily observable. Statistical analysis of these data must be interpreted with caution because changes in sampling techniques and analytical methods continually improve the accuracy of results. This is especially true where only one sample is available for a year (Kleiber and others, 1978). 


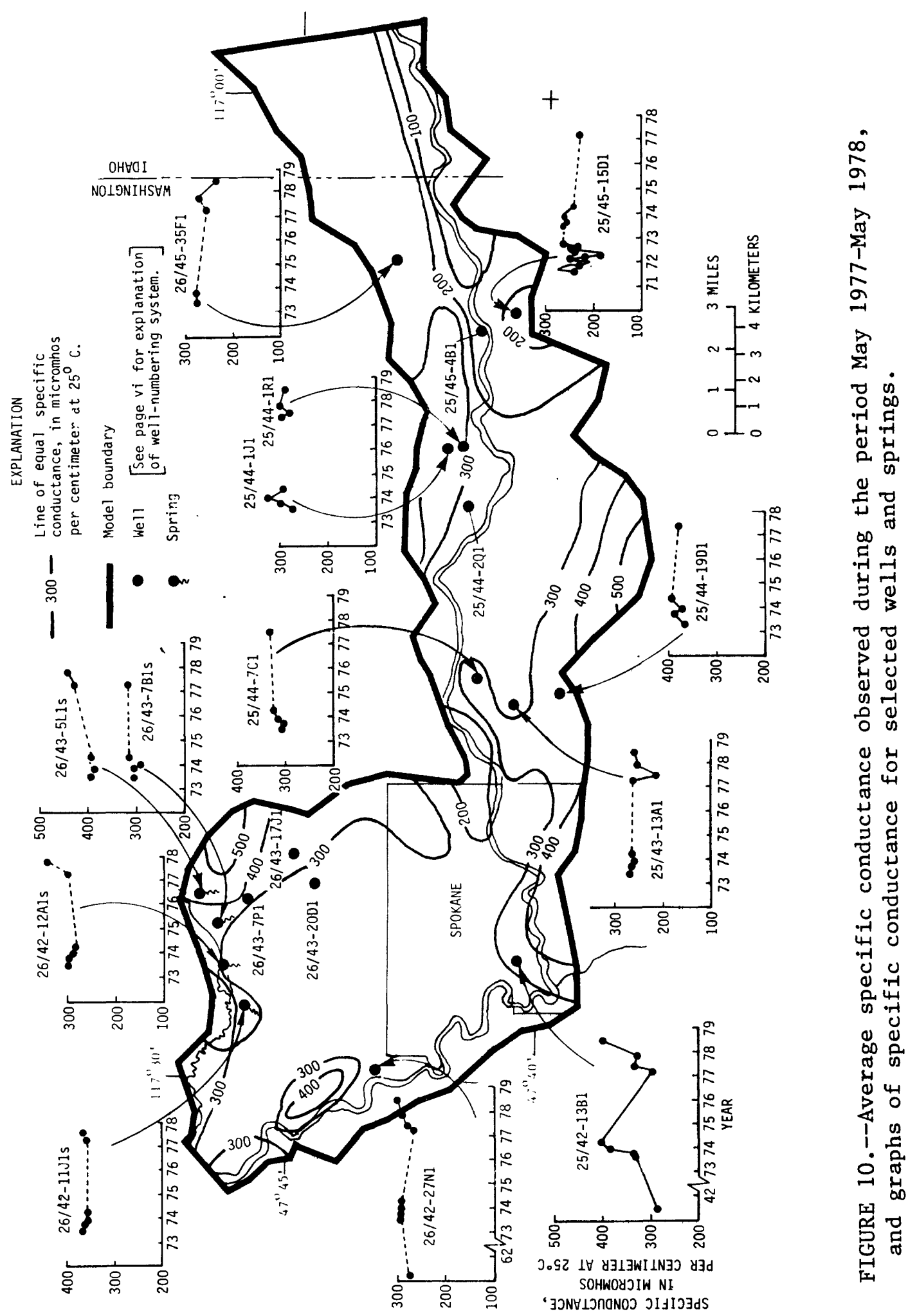


To assess the type of water prevalent in the Spokane aquifer, the data were plotted on diagrams designed to show dominant chemical constituents based on percentage composition (figs. 11 and 12). Regressions were then performed between specific conductance and the major dissolved constituents. Utilization of specific conductance as an indicator of the probable concentrations of other constituents is possible, based on the correlation coefficients shown in the table below.

\section{Constituent}

Dissolved solids

Hardness

Calcium

Alkalinity

Bicarbonate

Magnesium

Chloride

Sodium

Potassium

Ammonium

Nitrate

Sulfate

\section{Correlation \\ coefficient}

0.995

.978

.965

.952

.952

.915

.683

.565

.333

.181

.153

.128

Tight grouping of the data points, figures 11 and 12, shows that dissolved calcium and bicarbonate are the principal constituents in the ground water.

Some wells had atypical water types that were probably related to some local land-use loading. For example, water from well $25 / 44-2 \mathrm{Q} 1$ is characterized by its position in figures 11 and 12. This well, drilled near an aluminum processing plant, has a documented history of water-quality problems (Esvelt and Saxton, 1964; Drost and Seitz, 1978). The water-quality problems are related to industrial wastes deposited in a nearby gravel pit.

Dissolved chloride is not a predominant component in the water chemistry in the Spokane aquifer. The observed concentrations are generally low (observed range from 0.4 to $24.0 \mathrm{mg} / \mathrm{L}$, mean $=4.0 \mathrm{mg} / \mathrm{L}$, table 2) and there is a poor correlation with specific conductance. Chloride is, however, a major byproduct of much of the land use in the Spokane Valley. The effect of waste dumping was documented at an aluminum plant in which dissolved chloride in the affected ground water, in well $25 / 44-2 \mathrm{Q} 1$, increased from 7 to more than $130 \mathrm{mg} / \mathrm{L}$. The average observed chloride distribution for the study area for the period May 1977 to May 1978 is shown in figure 13. The most striking characteristic of the chloride distribution is the consistency through the entire central portion of the aquifer of the area where most concentrations are less than $2 \mathrm{mg} / \mathrm{L}$. About 72 percent of the 373 observed chloride values, valley-wide, were less than $4 \mathrm{mg} / \mathrm{L}$. Ground-water entering the valley at the eastern boundary has a chloride concentration of about $1.0 \mathrm{mg} / \mathrm{L}$. Most ground water with lower chloride values can be directly attributed to river leakage--for example, well number 25/45-9B1, with an average chloride concentration of $0.8 \mathrm{mg} / \mathrm{L}$. As discussed later in the Calibration section of this report, higher chloride concentrations in the ground water of the peripheral areas is attributable to boundary inflows and land use. 


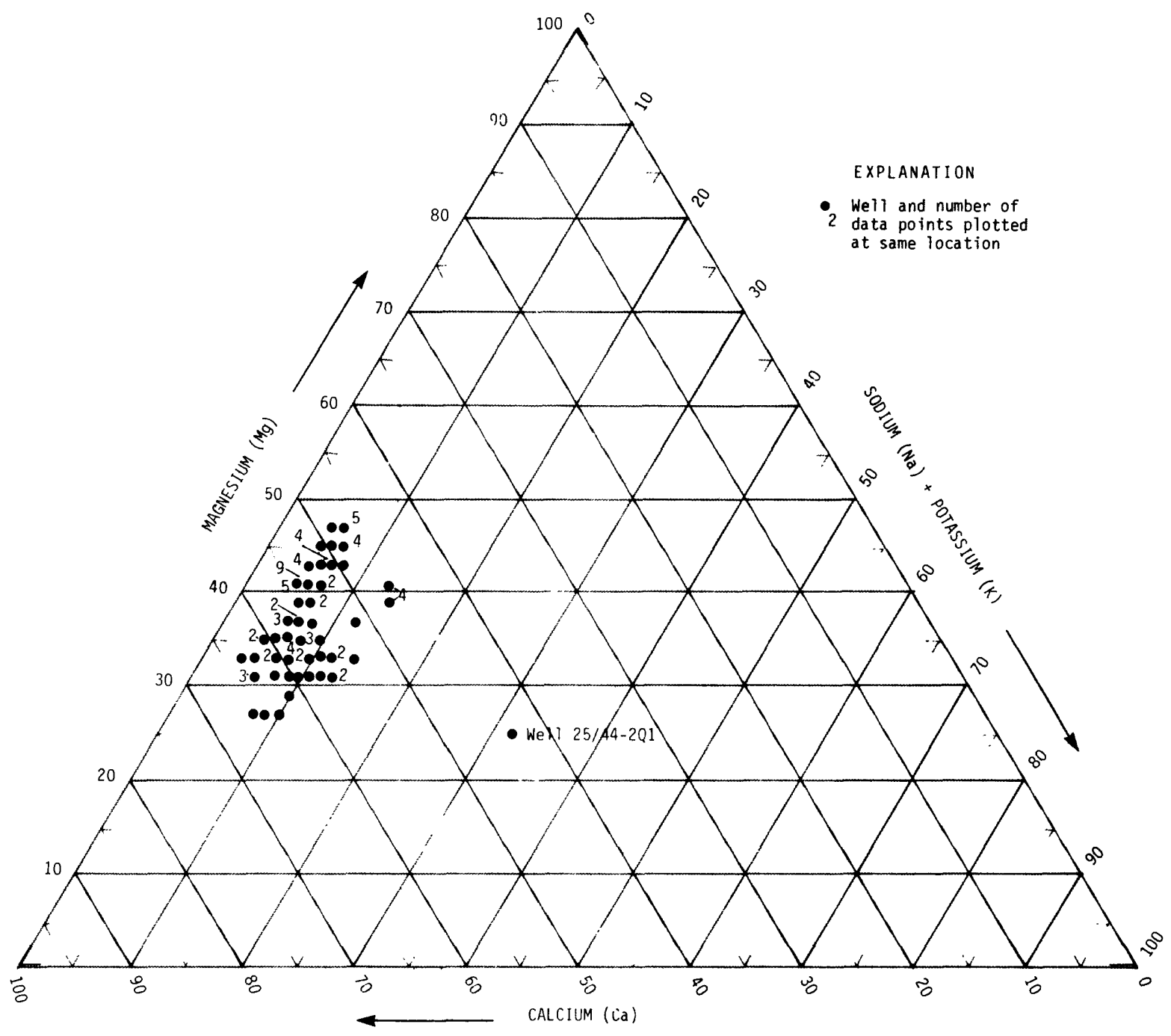

FIGURE 11.--Relative percentages of cations in water from selected wells in the Spokane aquifer. 


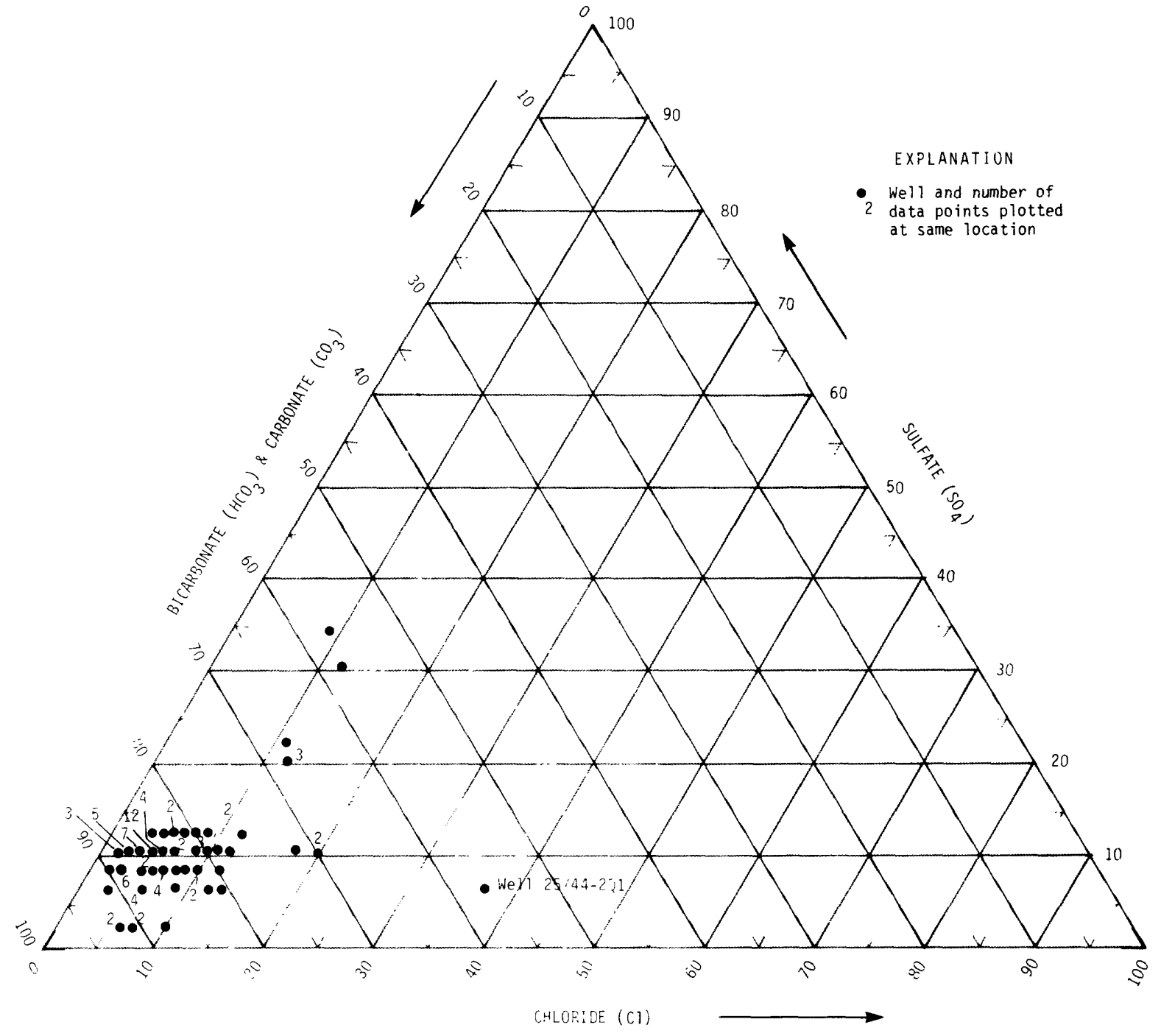

FIGURE 12.--Relative percentages of anions in water from selected wells in the Spokane aquifer. 


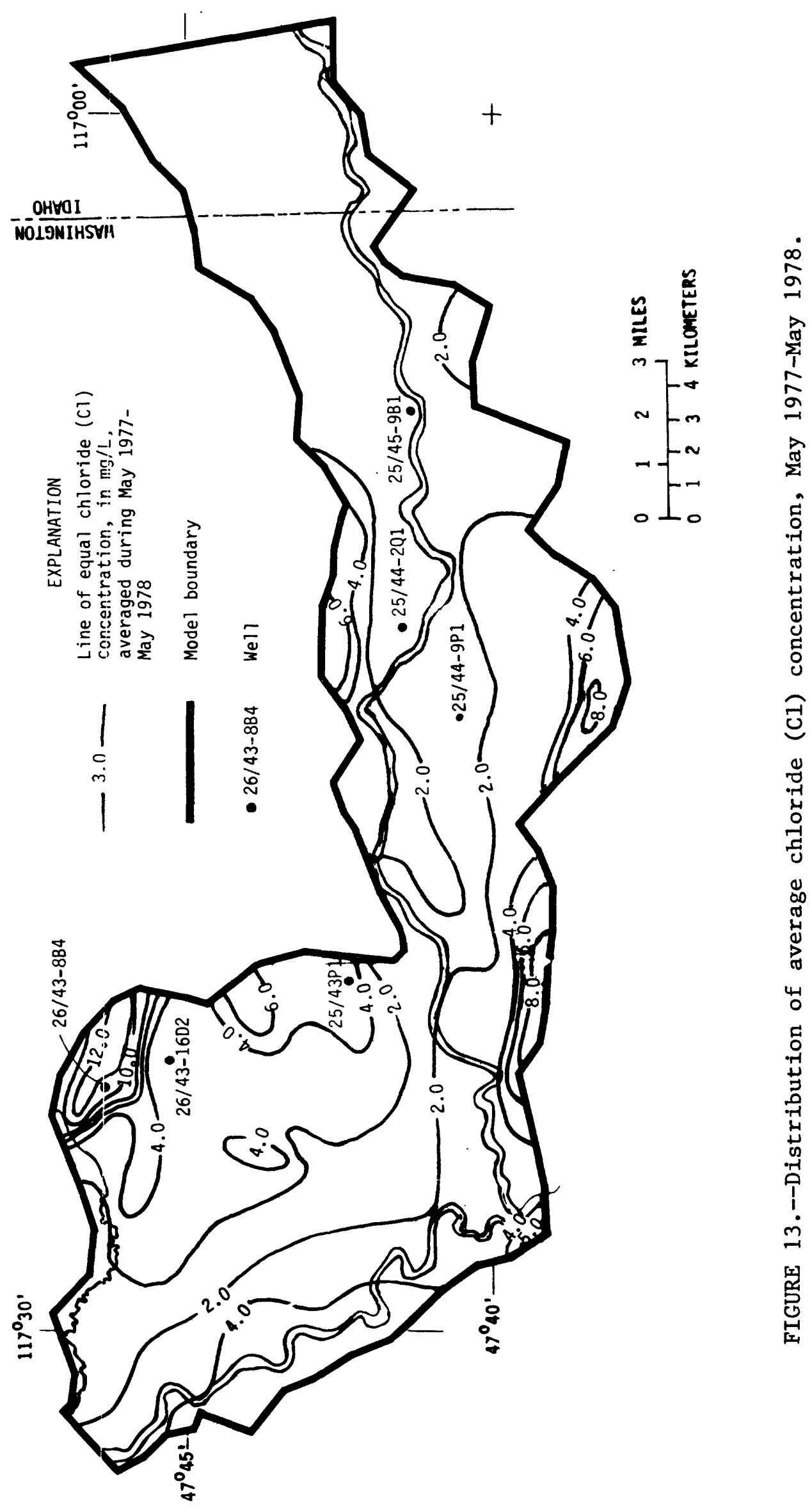


The cycle of nitrogen in the soil and unsaturated zone overlying the Spokane aquifer has not been quantitatively investigated. However, numerous studies have documented the general tendency in similar environments for the conversion of organic forms of nitrogen, through a series of biochemical oxidation reactions, to inorganic forms, ending with nitrate $\left(\mathrm{NO}_{3}\right)$, the mobile and most persistent form of inorganic nitrogen in the hydrologic environment.

Nitrogen can be a byproduct of land use in the Spokane Valley. Generally, agricultural activities, even in the absence of fertilization, will contribute nitrogen through plant fixation. Other activities, such as sewage disposal into the river and septic-tank effluent, are also probable sources of nitrogen. The Environmental Protection Agency's (1976) drinking water standard for nitrate, expressed as elemental nitrogen $\left(\mathrm{NO}_{\overline{3}}-\mathrm{N}\right)$, is $10 \mathrm{mg} / \mathrm{L}$. Because the nitrogen cycle is a continuous transformation of the nitrogen species from organic forms ultimately to $\mathrm{NO}_{3}-\mathrm{N}$, various components of the cycle were analyzed, and the observed ranges tabulated in table 2.

The ground water was analyzed for nitrate-nitrogen $\left(\mathrm{NO}_{\overline{3}}-\mathrm{N}\right)$, nitrite-nitrogen $\left(\mathrm{NO}_{2}-\mathrm{N}\right)$, ammonium-nitrogen $\left(\mathrm{NH}_{4}^{+}-\mathrm{N}\right)$, and kjeldahl nitrogen (organic nitrogen plus ammonium). About 85 percent of the observed nitrate values were less than 3 $\mathrm{mg} / \mathrm{L}$, and the mean nitrate concentration for each of the three sample periods (May 1977, October 1977, and May 1978) was 1.8, 1.7, and $1.8 \mathrm{mg} / \mathrm{L}$, respectively. Although ammonium is the predominant form of nitrogen in septic-tank effluent, insignificant amounts of $\mathrm{NH}_{4}-\mathrm{N}$ and $\mathrm{NO}_{2}-\mathrm{N}$ were observed in the ground-water system. This is assumed to be a result of the tendency for rapid oxidation of both $\mathrm{NH}_{4}^{+}-\mathrm{N}$ and $\mathrm{NO}_{2}-\mathrm{N}$ to $\mathrm{NO}_{\overline{3}}-\mathrm{N}$.

The general distribution of $\mathrm{NO}_{\overline{3}}-\mathrm{N}$ in water from the Spokane aquifer is shown in figure 14 by contours of the average $\mathrm{NO}_{3}-\mathrm{N}$ values over the study period. The temporal variation from the average $\mathrm{NO}_{\overline{3}}-\mathrm{N}$ values was, on the average, less than $0.2 \mathrm{mg} / \mathrm{L}$, so that the distribution shown adequately represent the areal $\mathrm{NO}_{\overline{3}}-\mathrm{N}$ distribution. As in the case of specific conductance and chloride, the lowest $\mathrm{NO}_{\overline{3}}-\mathrm{N}$ values occur in the east and central parts of the study area. Higher concentrations ivere observed near the aquifer boundaries.

$\mathrm{NO}_{\overline{3}}-\mathrm{N}$ should act as a conservative ion in the hydrologic environment in the absence of biochemical reactions. Therefore, if both chloride and $\mathrm{NO}_{\overline{3}}-\mathrm{N}$ originate from common sources, there should be a strong correlation between the concentrations of the two ions. The sample correlation coefficient between the observed nitrate: and chloride concentrations was 0.442 , indicating that there is low correlation in the water samples from the Spokane aquifer for nitrate and chloride. Two possible reasons for the low correlation are: 1) denitrification through microbial reduction of $\mathrm{NO}_{\overline{3}}-\mathrm{N}$ to nitrogen gas; and 2) derivation of $\mathrm{NO}_{\overline{3}}-\mathrm{N}$ and chloride from different sources. An example of the latter is shown by the chemical analysis of the water from well 26/43-34Pl (figs. 13 and 14), which is located in an industrial area. Water from this well had high chloride values, ranging from 11.0 to $20.0 \mathrm{mg} / \mathrm{L}$, but correspondingly low $\mathrm{NO}_{3}-\mathrm{N}$ values, ranging from 0.0 to $1.3 \mathrm{mg} / \mathrm{L}$. Similarly, well 26/43-16D2, which is located near an aluminum reduction facility, has an average chloride concentration of about $16 \mathrm{mg} / \mathrm{L}$ and an average nitrate concentration of $2.2 \mathrm{mg} / \mathrm{L}$. The nitrate values for the above two wells match the areal distribution of $\mathrm{NO}_{3}-\mathrm{N}$, but the chloride values are much higher than the surrounding chloride concentrations. This type of difference is not only indicative of point sources, but shows that the sources of the two ions can be different. 


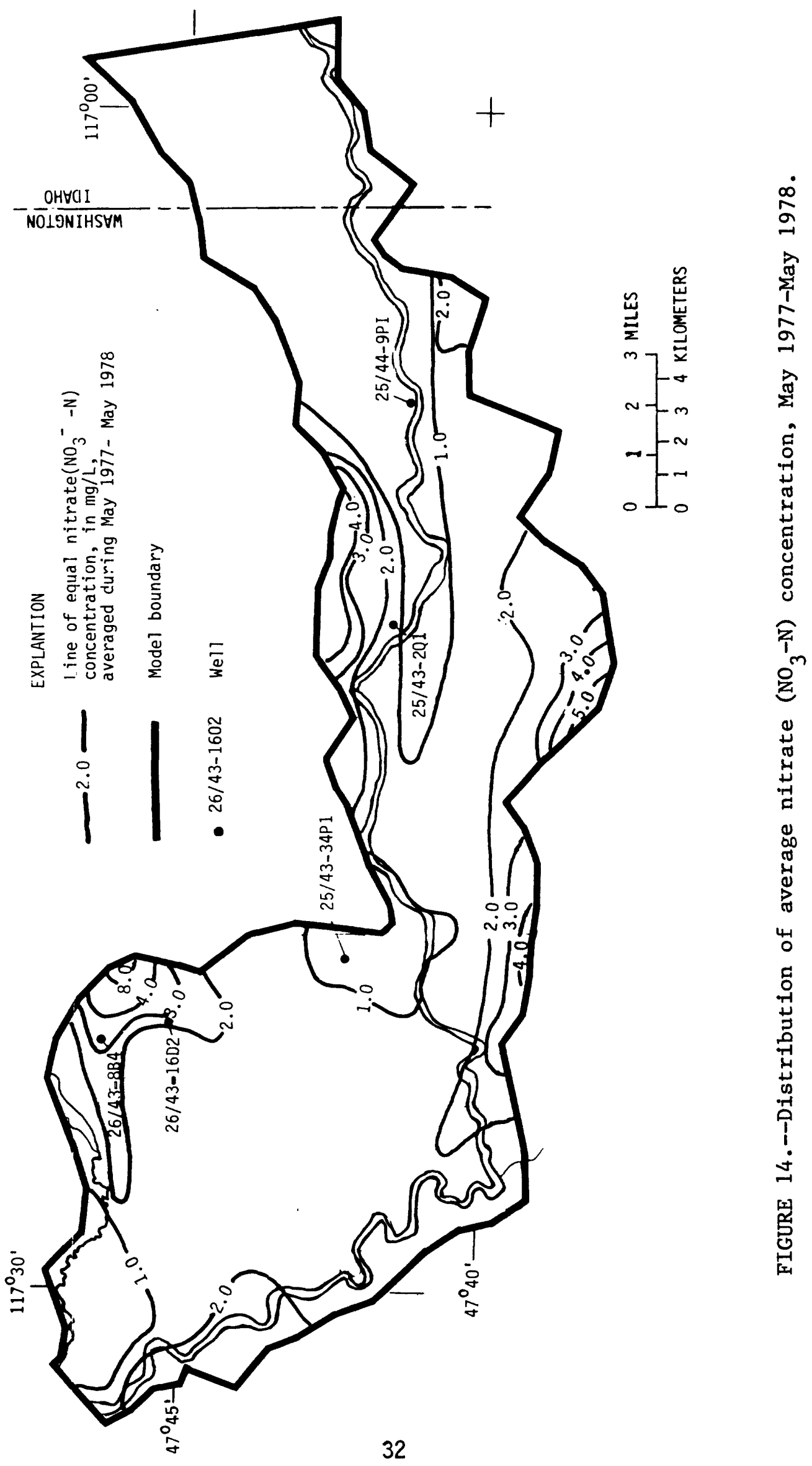


In some locations, there are both high nitrate and chloride concentration values. Three wells in the Mead area had $\mathrm{NO}_{3}-\mathrm{N}$ values greater than $8.0 \mathrm{mg} / \mathrm{L}$. The average chloride concentrations for water samples from these wells was also high--all were greater than $11 \mathrm{mg} / \mathrm{L}$. The concentration values are atypical for the Spokane aquifer, indicating that there is not only a common source for the two ions, but also that the water probably originates outside the study area. The specific-conductance values are also high for this area and correspond with the previous analysi:s that the water is derived from the boundary inflow from Peone Prairie. As the cyclic variations in the ground-water levels occur, there is a corresponding variation in the influence of the boundary mass flux, and there should be an area where the boundary water is mixed with the Spokane aquifer water. This seasonal variation and mixing was shown by analysis of the water samples from well $26 / 43-8 \mathrm{~B} 4$. The $\mathrm{NO}_{3}-\mathrm{N}$ values ranged from 1.8 to $8.4 \mathrm{mg} / \mathrm{L}$ and the chloride values ranged from 4.2 to $21.0 \mathrm{mg} / \mathrm{L}$. The highest concentrations occurred during the October 1977 sample period, when the water levels were low. Correspondingly, the specific-conductance value at this time was 630 micromhos, which is indicative of the conductance concentrations found at the boundary.

Observed nitrate values in the area south of Opportunity are also higher than in the rest of the ground-water system. These high values are caused not only by the mass flux entering at the boundary, but also are probably related to land-surface activities that can contribute nitrogen to the ground-water system.

Orthophosphate occurs in only minor concentrations in the water of the Spokane aquifer. This does not mean that it is not a significant constituent in septic-tank effluent; however, the effluent percolating to and recharging the ground-water system (direct-domestic recharge) will generally contain low concentrations. Most soils are capable of retaining large amounts of orthophosphate. However, the mechanisms of phosphorus adsorption and replacement in the soil are complex and are greatly affected by a number of physical and chemical factors. The observed variations in orthophosphate are more a function of any of a number of undocumented variables than of a particular land use, and therefcre the orthophosphate data were not interpreted. Table 2 includes the range of observed data, the mean of that range, and the standard deviation. The greatest variation in the orthophosphate data occurred in the vertical samples in the wells north of the Spokane city limits.

In summary, areal variations in chloride, nitrate, and specific conductance of the water in the Spokane aquifer are caused by river leakage, mass flux entering at the boundary, and land-surface activities. The largest areal and temporal variations were observed in the Mead area, and were caused by ground-water underflow (boundary mass flux) from Peone Prairie. Two other peripheral areas with high observed concentrations, south of Opportunity and north of Irvin, had smaller variations than the Mead area. These increased concentrations are attributed to land-surface activities and boundary inflow. 


\section{Vertical Water-Quality Variations}

Vertical water-quality variations were assessed by examining the average specific conductance and chloride values for wells sampled for the three sample periods. The location of the wells and their associated cross sections through the aquifer are shown in figure 15. The averages were computed for samples from the top 10 feet and the lower 40 feet of the sampled zone (table 3). Average values for each sampling interval were used in this analysis so that time-averaged concentration gradients could be detected. This method was also preferable because in a single water sample small-scale heterogeneities in a parcel of water, in conjunction with errors owing to sample handling and laboratory analysis, can cause in-sample variation (Kleiber and others, 1978). This is especially true when analyzing the water quality of a ground-water system that has low chemical concentrations where, for example, a $0.5-\mathrm{mg} / \mathrm{L}$ vertical change can be a 50 -percent increase or decrease in concentration. Temporal vertical variations were assessed along with the averaging procedure by an analysis of the data presented in figures 16-20.

Analysis of the data in table 3, along with vertical plots of the observed data (figs. $16-20$ ), indicates that there is no large difference in concentrations between the top 10 feet and the lower 40 feet of water in most of the sampled wells in the Spokane aquifer. The exceptions to this conclusion are discussed below. Four of the 13 wells listed in table 3, 26/46-31M6, 25/45-5R2, 26/42-29F1, and 25/44-17Rl, showed the largest differences in average specific conductance, about 30 micromhos, between the values of the top 10 feet and the lower 40 feet. The largest differences in average chloride concentration, about $1.5 \mathrm{mg} / \mathrm{L}$, were in wells 25/44-17RI and 26/42-27F1. Wells 26/46-31M6 and 25/44-9C2 showed average differences in chloride concentrations of about $0.2 \mathrm{mg} / \mathrm{L}$. Differences in averages for the remaining wells listed in table 3 for both specific conductance and chloride concentration are about 5 micromhos and $0.1 \mathrm{mg} / \mathrm{L}$, respectively. The largest vertical and seasonal changes of the observed constituents were in wells 25/44-17Rl (fig. 18) and 26/42-27F2 (fig. 20). Well 25/44-17R1 is located in an area where land-surface activities could contribute to increases in chemical constitutents in ground water because it is an unsewered residential and large commercial area. The water samples from this well showed vertical changes in specific-conductance values of about 100 micromhos and a chloride difference of about $4.5 \mathrm{mg} / \mathrm{L}$ for the October 1977 sample period. Well $26 / 42-27 F 1$ is adjacent to a large landfill, and the vertical variations and higher concentrations were due to constituents from the landfill. 
TABLE 3.--Mean and standard deviation of specific conductance and chloride for the top 10 feet, lower 40 feet, and total thickness penetrated below water table (approximately $50 \mathrm{ft}$ ), of wells sampled for vertical water-quality variations

Cross section (fig. 15) location

$26 / 46-30 D 1$
$26 / 45-25 \mathrm{JI}$
$26 / 46-31 M 6$

$2 \begin{array}{lll}26 / 45-33 N 1 & 326 / 11 \\ 25 / 45-5 R 2 & 342 / 24 \\ & 25 / 45-8 R 2 & 198 / 3\end{array}$

$25 / 44-9 C 2 \quad 274 / 23$

3

25/44-9P1

25/44-17R1

$305 / 11$

$280 / 50$

25/43-11M3

4

$266 / 10$

$288 / 30$
Specific conductance

(Mean/standard deviation)
Chloride

(Mean/standard deviation) Upper $10 \mathrm{ft}$

Lower $40 \mathrm{ft}$

Total $50 \mathrm{ft}$

$\begin{array}{lll}264 / 16 & 259 / 10 & 261 / 14 \\ 288 / 25 & 286 / 16 & 289 / 21 \\ 322 / 17 & 294 / 16 & 308 / 24\end{array}$

$0.93 / 0.19$

$0.95 / 0.24$ $0.83 / 0.14$ $1.20 / 0.27$

$0.94 / 0.21$

$0.84 / 0.12$

$1.37 / 0.33$

$0.84 / 0 / 13$

$1.30 / 0.31$

$\begin{array}{lll}-- & - & 2.10 / 0.10\end{array}$

$308 / 40 \quad 326 / 39$

$200 / 5 \quad 200 / 3$

$1.28 / 0.22$

$0.83 / 0.06$

$1.38 \overline{-0.26}$

$0.85 / 0.13$

$1.32 \overline{10} .23$

$0.83 / 0.10$

$279 / 18 \quad 274 / 21$

$302 / 10 \quad 303 / 10$

$254 / 21 \quad 269 / 42$

$2.04 / 0.46$

$1.81 / 0.58 \quad 1.91 / 0.47$

$1.49 / 0.29$

$3.68 / 1.92$

$1.46 / 0.27$

$1.47 / 0.27$

$2.14 / 0.53 \quad 3.09 / 1.77$

$271 / 10 \quad 268 / 10$

$279 / 19 \quad 285 / 26$

$1.12 / 0.04$

$2.40 / 1.03$

$1.14 / 0.10$

$1.14 / 0.08$

$238 / 11 \quad 238 / 10$

$1.80 / 0.05$

$2.52 / 0.83$

$2.44 / 0.93$

$1.75 / 0.32$

$1.78 / 0.41$

$242 / 16$

$244 / 16 \quad 244 / 16$

$2.01 / 0.16$

$1.92 / 0.19 \quad 1.98 / 0.17$

$26 / 42-27 F 1$

$7.62 / 0.16$

$6.99 / 0.61 \quad 623 / 0.15$ 


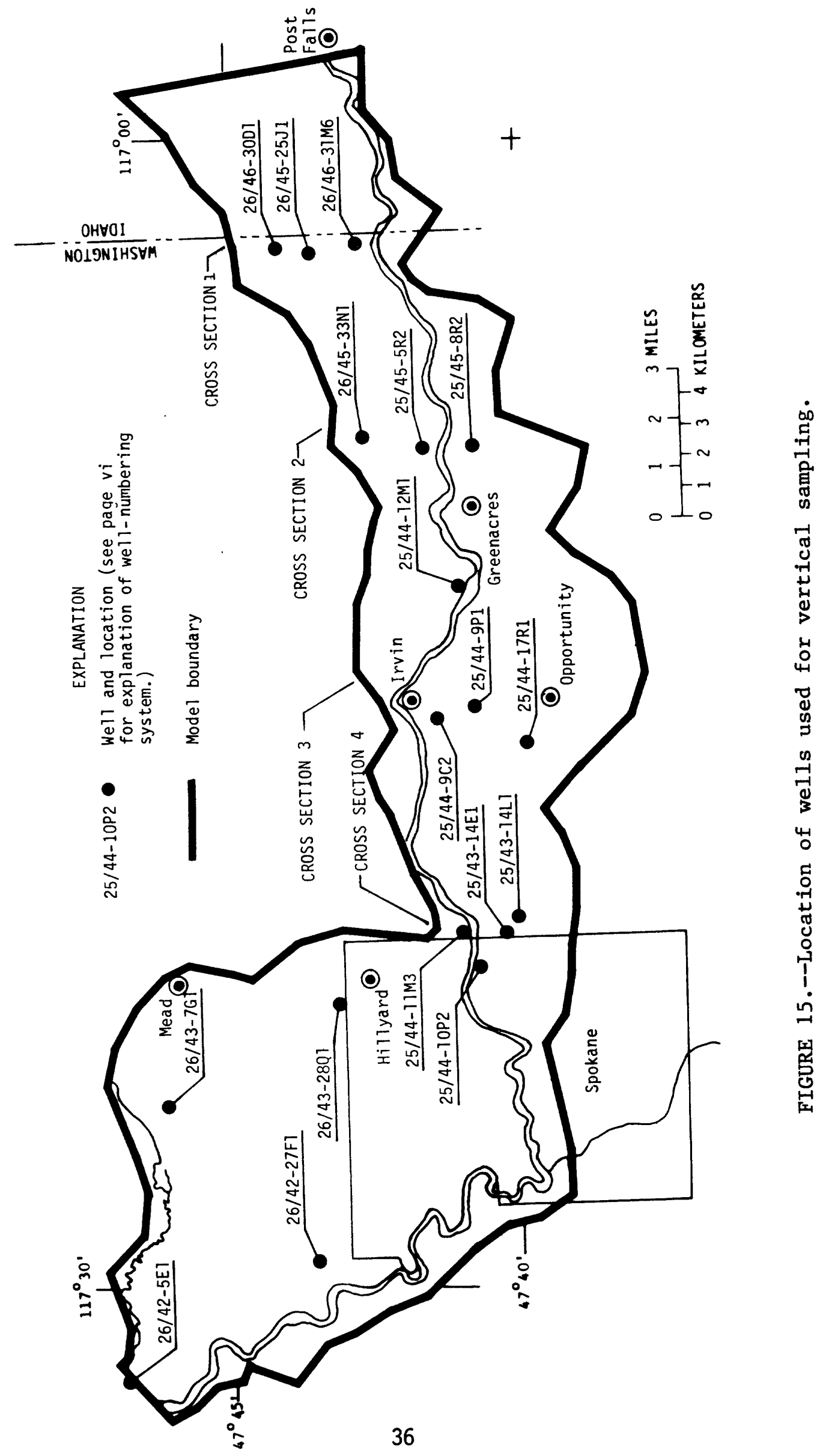



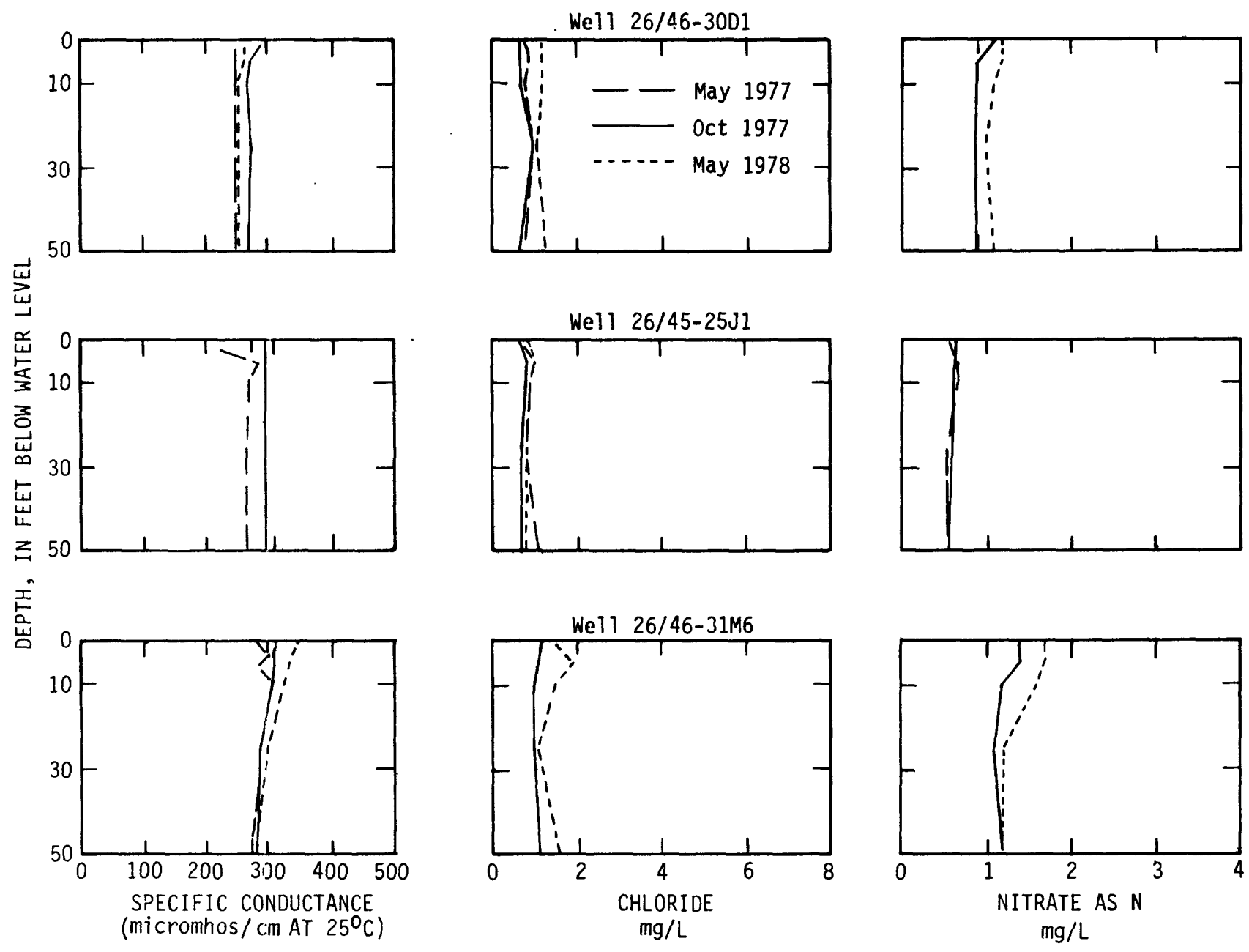

Well 26/45-25J1
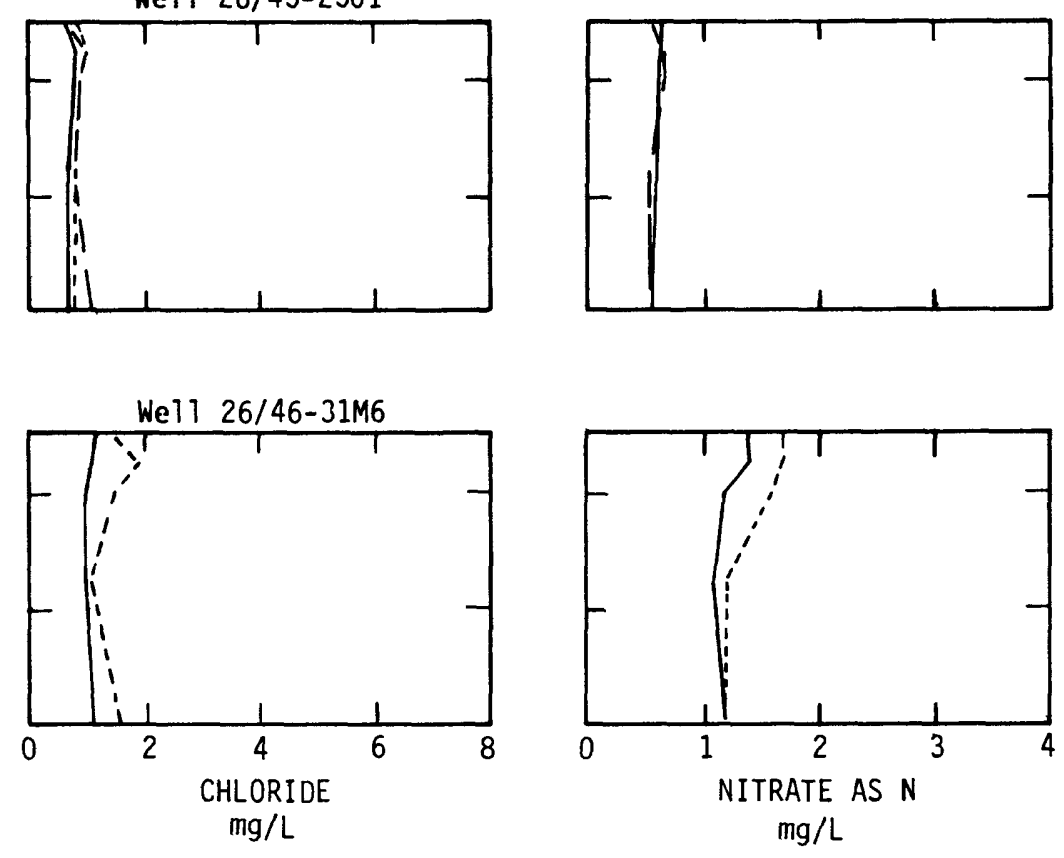

FIGURE 16.--Vertical variations in specific conductance, chloride, and nitrate-nitrogen in wells at cross-section 1 . 

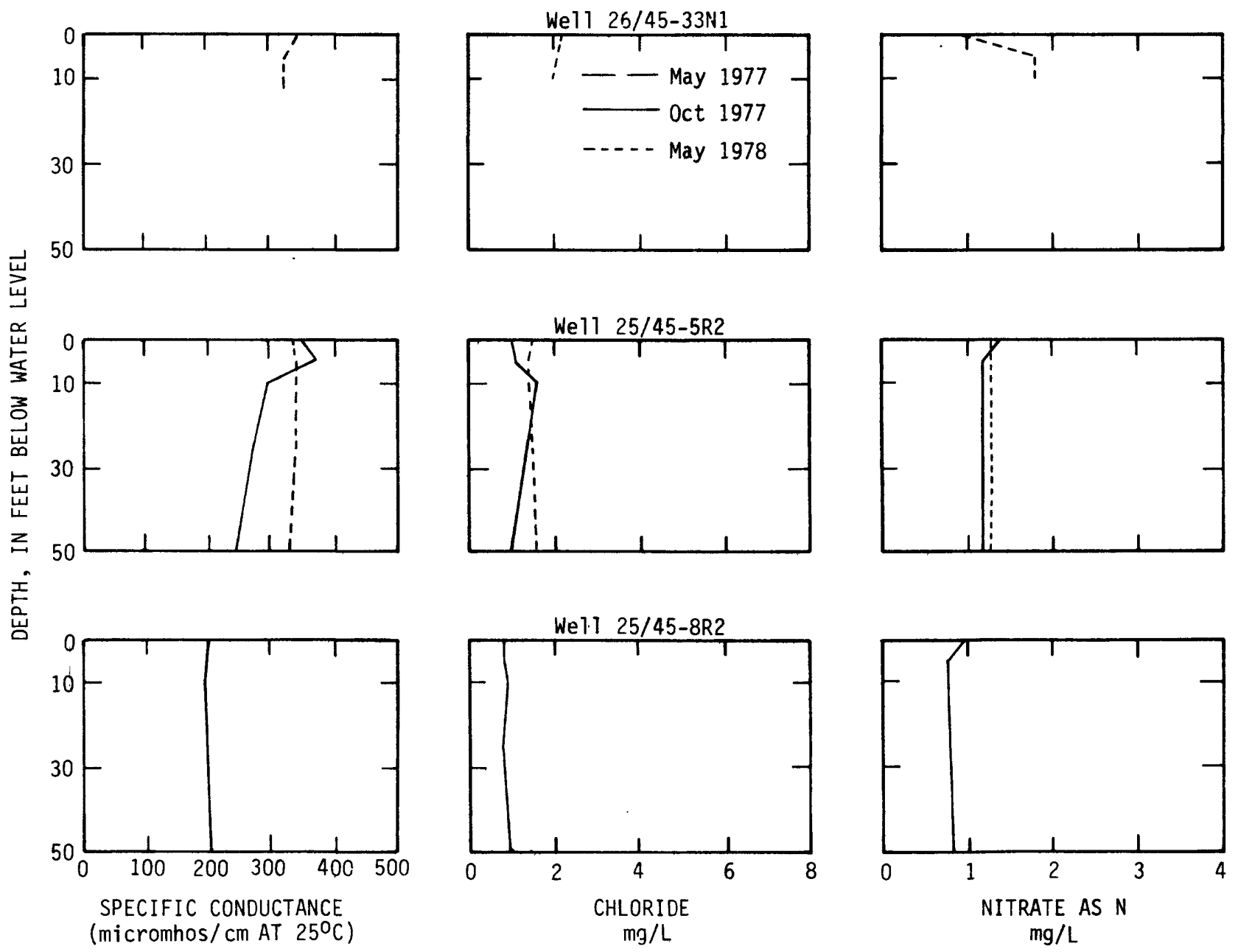

FIGURE 17.--Vertical variations in specific conductance, chloride, and nitrate-nitrogen in wells at cross-section 2 . 

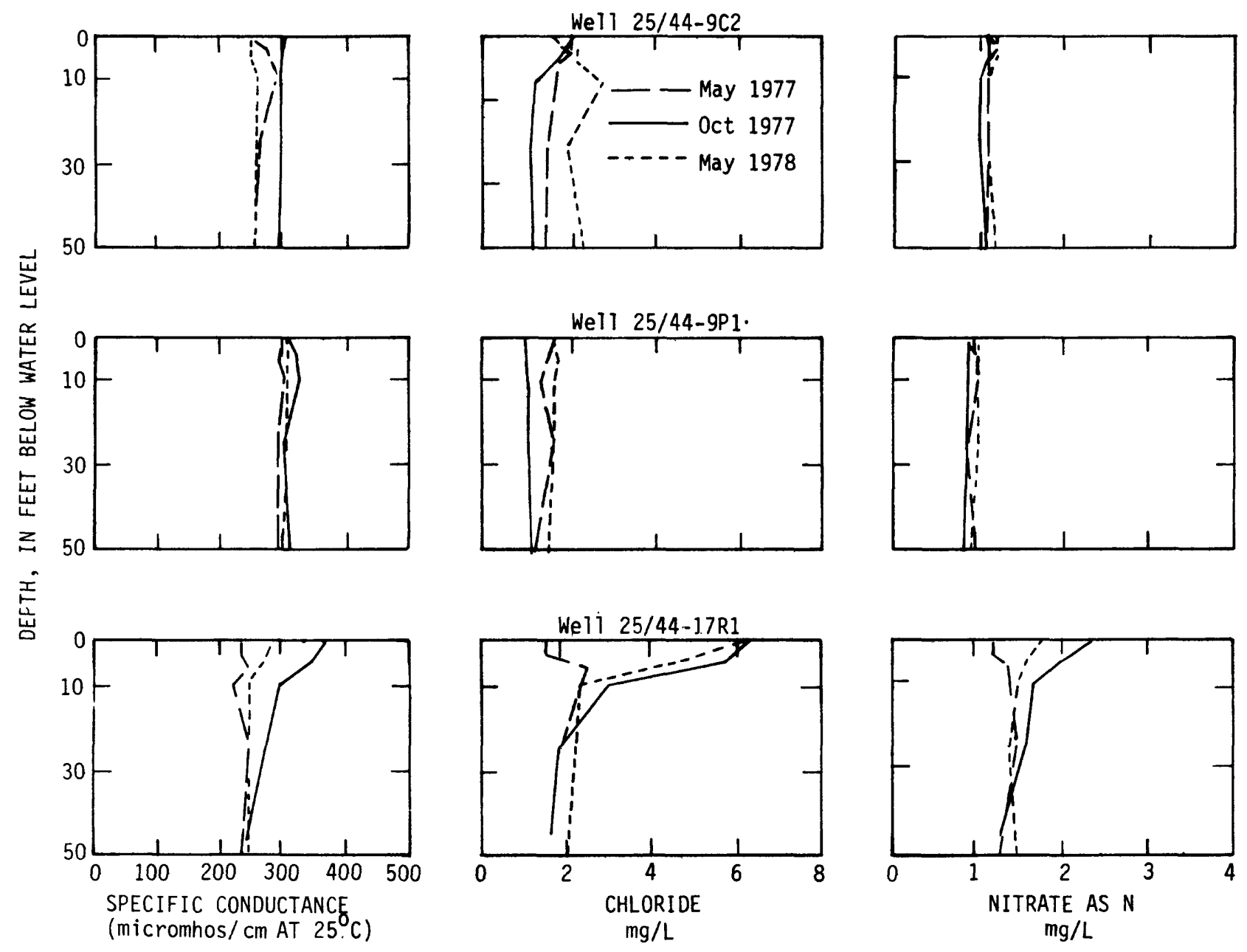

FIGURE 18.--Vertical variations in specific conductance, chloride, and nitrate-nitrogen in wells at cross-section 3 . 

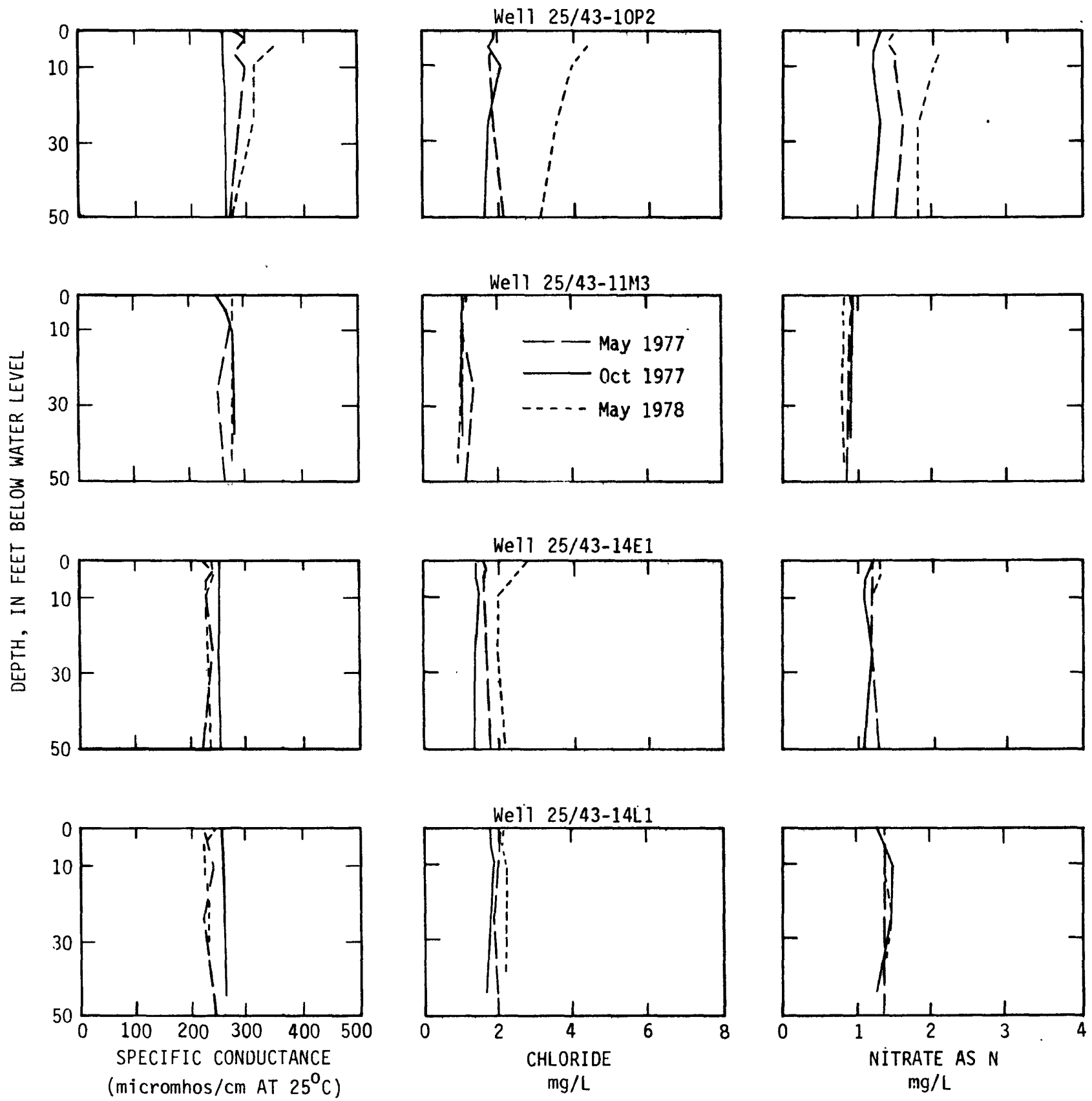

FIGURE 19.--Vertical variation in specific conductance, chloride, and nitrate-nitrogen in wells at cross-section 4. 


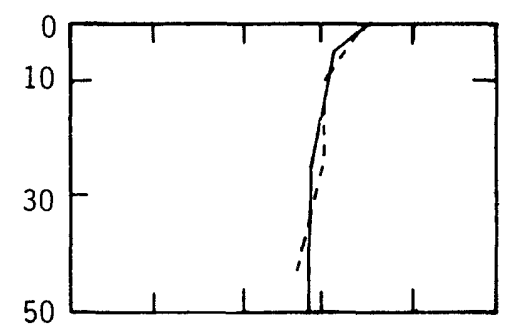

We11 26/43-28Q1
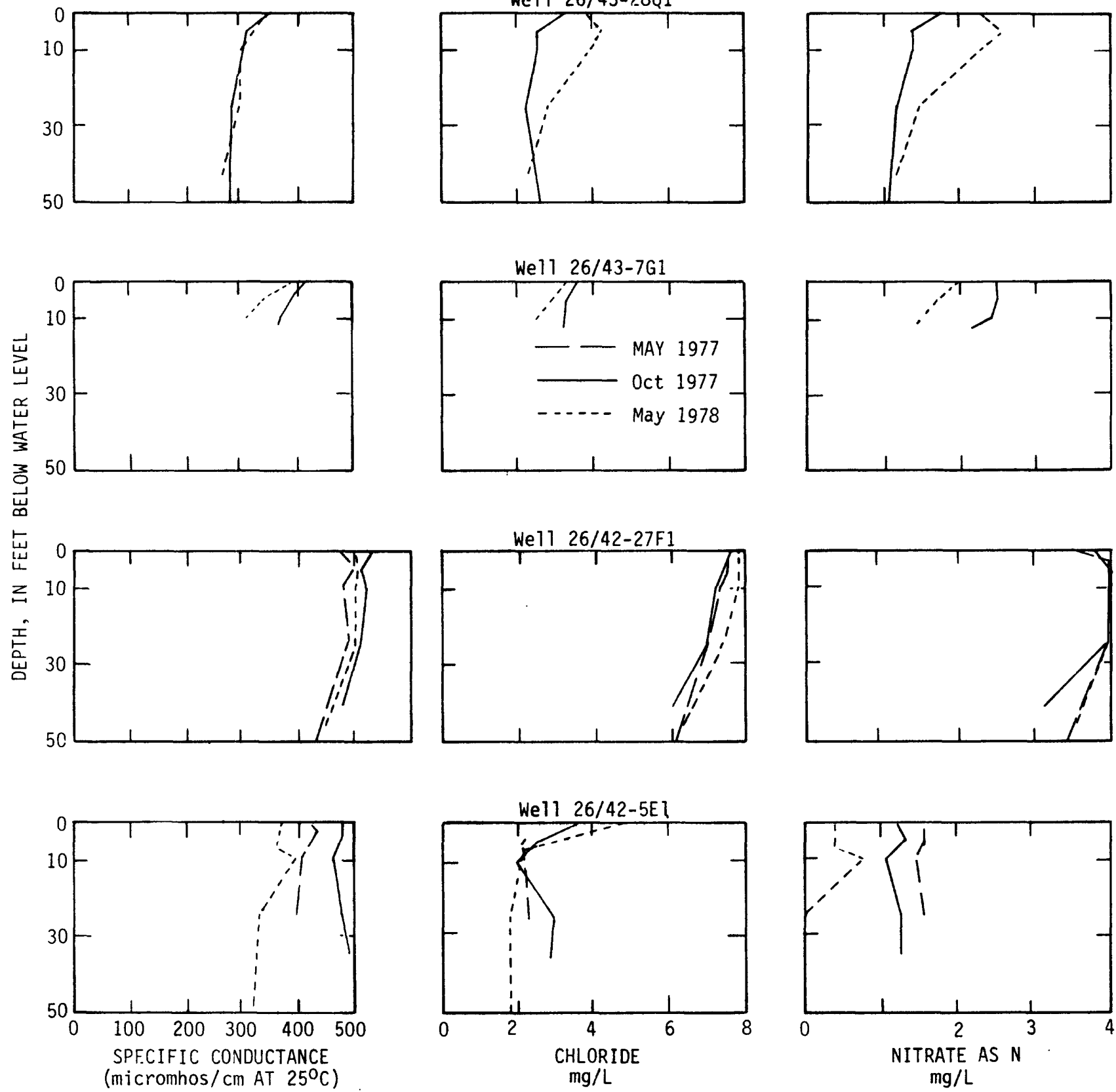

FIGURE 20.--Vertical variation in specific conductance, chloride, and nitrate-nitrogen in wells north of the Spokane city limits. 


\section{MODEL CONSTRUCTION AND CALIBRATION}

A digital model that simulates the physics of ground-water flow and mass transport can provide a better understanding of the aquifer and permit predictions of future water levels and water-quality changes. The model is a mathematical approximation of the real system, which is inherently complex. Consequently, such an approximation will not entirely duplicate flow and movement of chemical constituents in the aquifer; it does, however, represent the best available description of the system.

The digital model used in this study calculates river discharge, water levels, and dissolved-chloride concentrations as a function of space and time. The model incorporates aquifer parameters, pumpages, and chemical loadings at points in a grid network, along with initial and boundary conditions for ground-water flow and mass transport.

\section{Flow Model}

The ground-water flow model of the Spokane aquifer is described in Bolke and Vaccaro (1981). An additional calculation required for the mass-transport model is the discharge per unit width of aquifer, which is also used to calculate a vertically integrated velocity field throughout the aquifer (fig. 7).

\section{Mass-Transport Model}

The model of two-dimensional areal mass transport of chloride used in this report is documented in Tracy and Vaccaro (1981), and is formulated rnathematically, given the following assumptions:

1. chloride ion is conservative;

2. ground-water movement is horizontal;

3. recharge is vertical and reaches the water table with no delay during transit in the unsaturated zone;

4. mass density of the ground water remains constant;

5. model parameters are representative of the average over the vertical; and

6. dispersion can be represented by a "Fickian type" relationship.

Incorporating the above assumptions, the mass-transport equation used in the numerical model is written as

$$
\theta b \frac{\partial c}{\partial t}+\underset{\sim}{q} \cdot \nabla_{H} c-\nabla_{H} \cdot D_{m n}^{*} \nabla_{H} c=Q\left(c^{\prime}-c\right)
$$

where $b$ is the saturated thickness, $L ; c$ is the mass concentration of the dissolved species chloride, $\mathrm{m} / \mathrm{L}^{3} ; \mathrm{D}_{\mathrm{mn}}$ is the two-dimensional vertically integrated hydrodynamic dispersion, $\mathrm{L}^{3} / \mathrm{T} ; \mathrm{q}$ is the discharge per unit width of the aquifer over the saturated thickness, $L 2 / t ; \sigma$ is the volume source per unit surface area, $L / t ; t$ is time, $t ; O$ is effective porosity, Lo; $c^{\prime}$ is mass concentration of volume source, $\mathrm{m} / \mathrm{L}^{3}$; and $\nabla_{\mathrm{H}}$ is the horizontal del operation. This partial differential equation 
must be approximated numerically for computer solution. The approximation used is the Galerkin method of weighted residuals (Finlayson, 1972), in conjunction with a finite-element spatial discretization. A detailed description of the finite-element method is presented in Hutton and Anderson (1971). This coupled method has been shown to yield accurate solutions with a minimum number of computations (Smith and others, 1973, and Duguid and Reeves, 1976) when applied to mass-transport problems in which both dispersive and convective flux of solutes occur.

Given the assumptions that underly the development of equation 4 and the incorporation of the source term (last term on left-hand side of equation 4) into the equation the numerical model is actually a representation of the conceptual model of the movement of conservative substances in the aquifer. The method of movernent and redistribution of a conservative substance through the source term represent another conceptual model. The various aspects of this model, both numerical and conceptual, was discussed in the Recharge to and Discharge from the Study Area section and in the following subsection.

The solution of the equation requires estimating the aquifer parameters: porosity, saturated thickness, and longitudinal and transverse dispersivities. Porosity and saturated thickness are only needed when the time-dependent term is included in a solution; in other words, a transient simulation. Aquifer dispersivities are related to the geometry of inhomogeneitics of the porous media and are length scale-dependent. They are used in conjunction with the discharge per unit width to compute the hydrodynamic dispersion. The dispersivities are estimated during the calibration process and are needed for either time-averaged or transient solution of the equation.

The mass-transport model as constructed for this study is best used for regional land-use impact modeling. The time-averaged mass-transport model can be used to determine the time-averaged chloride concentration field resulting from one or several point sources either to the river or ground-water system. The transient model can be used to qualitatively determine time-varying changes in the concentration field for regional land-use changes. The transient model was not developed to explicitly follow a concentration plume, and interpretations of computed output from this type of transient analysis can be erroneous. However, due to the physical characteristics of the Spokane aqufier, the transient model could be used for qualitative plume tracking if the model time step is chosen to correspond to the dispersion and velocity length scale that is at least of the same order of magnitude of the size of the finite elements.

\section{Calibration}

Calibration of the mass-transport model was accomplished through the following steps: 1) estimating initial aquifer chloride loadings from domestic-direct and land-surface-applied recharge; 2) assigning boundary fluxes of chloride, based on field data; 3) altering regional dispersivity of the aquifer in successive model iterations to find the general range of the regional dispersivities; and 4) then allowing the applied water concentration, which is dependent upon aquifer concentrations, to vary (they were not specified) and also allowing the regional 
aquifer dispersivities to vary until a statistically good fit was obtained between the observed and simulated chloride distributions. Following this, the sensitivity of the model to various sources of chloride was tested. This study included a time-averaged calibration, using the average conditions over the period May 1977 to May 1978, and a transient simulation, where changes in river discharge, water levels, and chloride concentrations during this period were simulated. When a reasonable match is achieved between observed and predicted variables, some confidence can then be placed in the model predictions of these variables. However, the assumptions made for this modeling effort, combined with a lack of data over the study area, preclude total confidence in the results, particularly with regard to the transient model. By updating the model periodically with additional data, confidence in the simulated results can be increased.

The time-averaged flow model was calibrated using the average annual values for the study period for pumpage, river discharges, precipitation, boundary conditions, and tributary inflows. Calculated time-averaged water levels are shown in figure 21. Bolke and Vaccaro (1981) give comparisons of measured and calculated water levels, as well as measured and calculated river discharges in both the Spokane and Little Spokane Rivers. The time-averaged fluid-flow water budget was discussed earlier in the section Recharge to and Discharge from the Study Area.

The time-averaged mass-transport model was calibrated by comparing simulated chloride values with the observed averages of chloride concentrations at 138 wells sampled between May 1977 and May 1978. The average chloride values were assumed to be the result of the transport and redistribution of chloride derived from the following souces: 1) boundary inflows and outflows; 2) stream leakage; 3) infiltration of water applied at the land surface; 4) infiltration from precipitation; 5) subsurface direct recharge from domestic and municipal sources; and 6) industrial discharges to the Spokane River.

Concentrations of these sources must be adequately defined in order to model the chloride distribution in the ground water and in the two rivers. Two methods were used conjunctively to define the concentrations of the sources and sinks. The first method applied for sources that originate outside the modeled region (boundary inflows, precipitation, and the rivers at point of entry to the modeled region) and for sources that upon utilization produce an effluent concentration independent of the ground-water concentration (industrial, septic tanks, and sewage-treatment plant effluents). In this method, a concentration was assigned (specified) to these sources, based on observed data, or estimated from values reported in the literature. In the second method, for sources that originated inside the modeled region (land-surface-applied water and boundary outflows) or for sources that are dependent upon the ground-water concentration (river gains and losses), the model actually computes these concentrations.

Boundary conditions for the time-averaged calibration were the chloride averages calculated from field data. These concentrations were assigned to all boundary inflow nodes (fig. 22). Specified-flux (Neuman) boundary conditions were used at all boundary inflow nodes, except the eastern (upstream) boundary. Specified-flux chloride boundary conditions were computed as the product of the water inflow from the flow model and the average chloride concentration. Chloride concentrations were specified along the eastern (upstream) boundary. The 


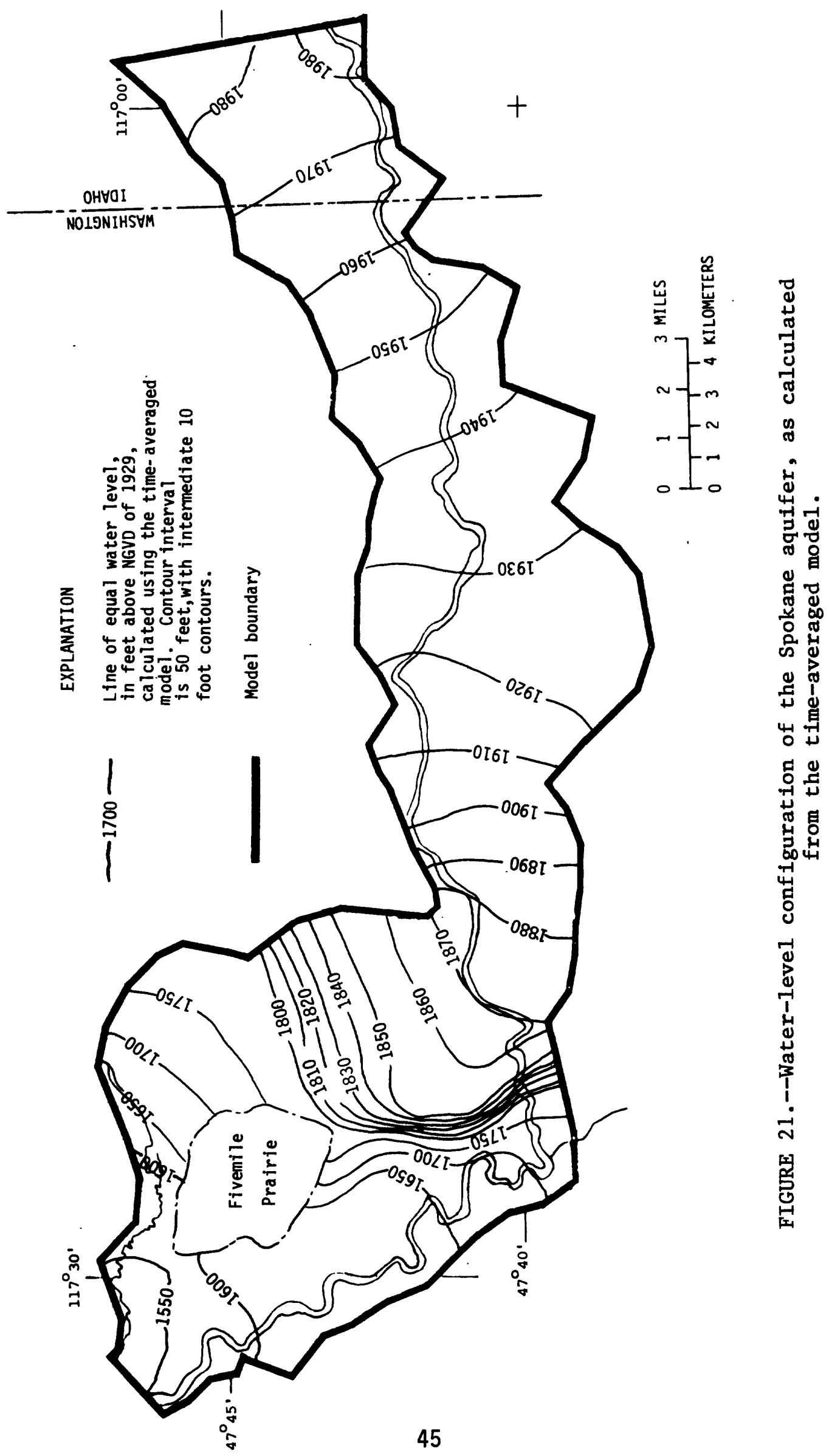




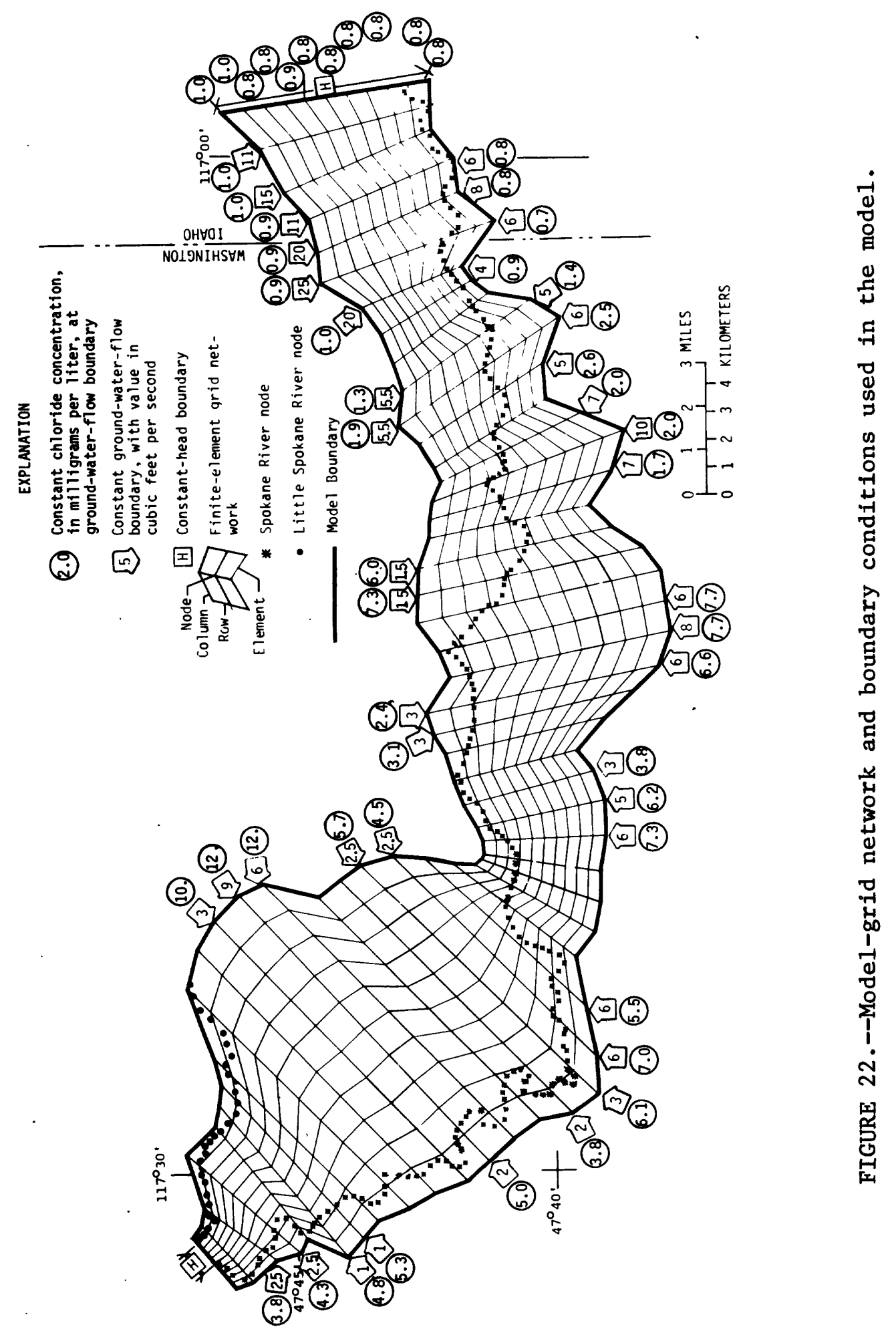


western (downstream) outflow boundary used a variable-seepage flux boundary condition for the chloride model because the concentration at the outflow nodes is assumed to be unknown and is dependent upon the internal concentration field.

The model simulated flow in the Spokane and the Little Spokane Rivers and movement of water and chloride between the rivers and ground-water system. The Spokane River was segmented into 203 nodes and the Little Spokane River into 86 nodes (fig. 22); at each one of these nodes the river discharge and stage was computed. The aquifer heads and concentrations surrounding a river node and the stage in the river of that node were then used to determine water and chloride flux between the aquifer and river at that node.

Movement of chloride into the model area via the Spokane River was simulated by assigning a value for the chloride concentration of $0.6 \mathrm{mg} / \mathrm{L}$ to the first (most eastern) river node, and for the Little Spokane River a chloride concentration of 1.7 was assigned to the first river node. These values represent the average chloride concentration measured in the river from May 1977 to May 1978.

The model uses river discharge, gains or losses between the river and ground-water system, and point sources or sinks in the river and their respective chloride concentrations to calculate a chloride concentration for each successive downstream river node. Complete mixing in the river between nodes is assumed in the model. The computation of mass concentration is started with the input of the initial concentration at the first river node. The concentration at the next river node is then calculated from the relationship

$$
c_{\text {node }+1}=\frac{q_{\text {in }} c_{\text {in }}-q_{\text {out }} c_{\text {out }}+q_{\text {node }} c_{\text {node }}}{q_{\text {in }}-q_{\text {out }}+q_{\text {node }}}
$$

where $q_{i n}$ is the flux of water entering the river between the two nodes from the aquifer and(or) external sources and has an associated concentration $\mathrm{c}_{\mathrm{in}}$, which is the concentration of the aquifer at that node or the concentration of a source, and qnode is the river discharge at the node upstream of where the concentration is being computed. The term qout is either: 1) the flow from the river to the aquifer, having an associated concentration cout equal to the concentration of the river water entering the node, cnode ; or 2) the rate of withdrawal from the river by pumping or diversion.

Water that recharges the ground-water system from the land surface was assumed to be derived from two sources, effective precipitation and water applied to the land surface by human activity. The latter consisted of lawn watering and agricultural irrigation and is water obtained by ground-water pumping. Chloride concentrations of recharge to the ground-water system derived from lawn watering and agricultural irrigation were allowed to vary spatially. The values arrived at were the values of the pumped source water computed by the model. No data for chloride concentration of precipitation were available for the Spokane area, and, therefore, the authors estimated a value of $0.5 \mathrm{mg} / \mathrm{L}$ based on the work of Hutchinson (1957), Eriksson (1952), Collins and Williams (1933), and the chloride concentration of: rainfall near Boise, Idaho, measured by the Agricultural Research Station (Stevenson, written commun., 1977). 
The chloride concentration of subsurface direct recharge (septic-tank recharge) from domestic and industrial sources was assigned a value of $50 \mathrm{mg} / \mathrm{L}$. This value was estimated from the results of a Utah State University Foundation study (1969) and a 1973 study by the University of British Columbia (Viraraghaven and Warnock, 1976).

The city of Spokane and Millwood City both discharge effluent from sewage-treatment plants into the Spokane river. The Millwood City discharge was neglected for modeling purposes because of its small load input into the river, less than 1 percent of the load in the river. Spokane's sewage-treatment plant is treated as a point source to the river. The quantity of water discharge from the treatment plant that is computed by the flow model was assigned an effluent concentration of $85 \mathrm{mg} / \mathrm{L}$ (L. Esvelt, written commun., 1980).

Industrial pumping sources were separated into three types: water discharged to the City of Spokane's Sewage Treatment Plant, water discharged directly to the ground-water system, and water discharged to the river. Discharge from the first type was accounted for in the treatment of the Spokane sewage discharge discussed previously; otherwise, each industrial discharge was assigned an effluent concentration and the discharges from the latter two types were either put into the river as point sources or discharged directly to the ground-water system. Effluent concentrations were obtained from a compilation of industrial usage of ground water presented by U.S. Army Corps of Engineers (1976).

Part of the water applied to the land surface from precipitation and from lawn watering and irrigation is lost by evapotranspiration (ET) in late spring, summer, and early fall. The water that is lost is assumed to be pure water. Thus, the total volumetric recharge from the land surface was decreased by the ET, increasing the concentration of dissolved solids in the recharge water. This procedure allowed the total chloride mass flux from land-surface-applied water to the aquifer to remain constant as long as there was water available for recharge after the ET demand had been satisfied.

Once the initial values for the sources of chloride inputs to the model were selected, the predicted chloride distribution was compared with the average of the measured chloride concentrations for the three sampling periods. Values of the longitudinal and transverse dispersivities were then progressively changed until an acceptable match between the calculated and predicted values of chloride was obtained. Following this, the sensitivity of the model to each of the estimated chloride sources--land-surface-applied waters, boundary concentrations, and domestic direct recharge--was tested.

\section{Calibration of Regional Dispersivity}

Longitudinal and lateral or transverse dispersivities were estimated at the regional scale by fixing ratios of transverse to longitudinal dispersivity and then varying the longitudinal dispersivity for each ratio. The ratios tested in this procedure were $0.2,0.3$, and 0.4 , and represent the ratios of transverse to longitudinal dispersivity most commonly found in transport modeling literature (Cherry and others, 1975). The computed concentrations at specific nodes were 
then checked against the averaged value of chloride calculated from the observed data. The following statistics were computed for each ratio for five values of longitudinal dispersivity: 1) the $r$-squared value (a measure of the amount of variation in the observed chloride values that can be accounted for by the model), which is defined as the square root of the sum of squares of the predicted values at water sanple points minus the mean of the observed values divided by the standard deviation of the observed values; and 2) the mean and standard deviation of the observed, model predicted, and residual (predicted value minus observed value) chloride concentrations at the water-sample points. In addition, the predicted spatial distribution of chloride values was compared with observed values in selected localized areas. The goal of the calibration was to try to minimize the mean residual and the sum of squares of the residuals and to simultaneously approach a $r$-squared value as near to 1 as possible. The residuals were also examined by plot:ting them at the observation points to determine if the residuals were randomly distributed. It was found that the residuals exhibited no particular spatial pattern with respect to their magnitude and size (fig. 23). The final values arrived at for the regional longitudinal and transverse dispersivity were 300 feet and 90 feet, respectively.

During the calibration of dispersivities, it was found that within a range of lateral dispersivities of \pm 80 feet for the 0.3 ratio the overall computed concentration fie:ld matche $\bar{d}$ well and as measured by the mean-predicted value at water-sample points, the mean variation was less than 5 percent. However, the model was sensitive to the other ratios and the matches were not as good. The match between :he observed and predicted values in areas of high concentration gradients was more important in the +80 feet range than the computed statistics showed. Advection is the dominant transport mechanism in the Spokane aquifer, and thus it was rot expected that the dispersivities would be very sensitive within a physically reasonable range, as found in modeling literature.

\section{Sensitivity Analysis}

After the model was calibrated for the regional longitudinal and transverse dispersivities, it was then tested for the sensitivity of computed chloride values to input chloride loadings. Model sensitivity to the loadings was estimated based on: 1) the same statistics that were used for calibration, and 2) the observation of the changes in nodal concentrations of chlorides between previous and newly computed chloride-concentration fields.

Because the boundary inputs to the model were based on observed data, and chloride fluxes from domestic-direct recharge and land-surface-applied recharge were assumed, a sensitivity analysis was made not only to determine the sensitivity of the model (thiss, the 'real' system) to these two sources of recharge, but also to determine if the two sources were necessary to account for the observed average annual chloride distribution. With domestic-direct recharge removed from the model, the overall match between calculated and predicted chloride values was still acceptable, although in local areas, where there exists relatively low transmissivity and high unsewered population density, the predicted values generally fell below the observed values. Evidence of the improvement of the statistical match can be seen by comparing the two methods, as shown in the table on page 51. 


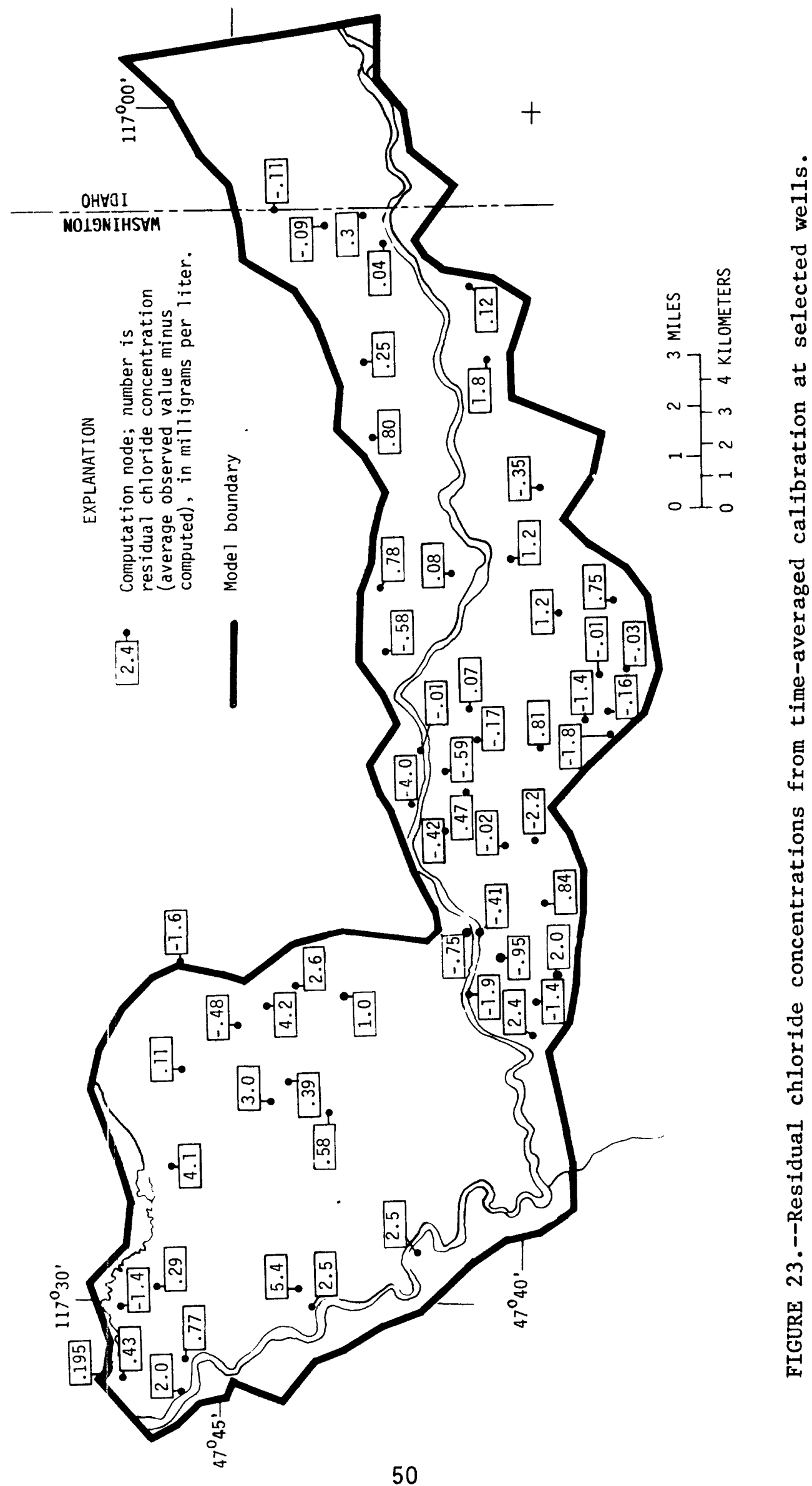


$\underline{\text { Statistic }}$

Domestic-direct: recharge removed

Mean

Standard deviation

Domestic-direct: recharge added

Mean

Standard deviation

$r$-squared value
Chloride Concentration (mg/L)

Observed Predicted Residual

$\begin{array}{rrr}3.25 & 1.88 & -1.37 \\ 3.06 & 2.52 & 1.77\end{array}$

3.25

2.78

2.75

0.83
$-0.47$

1.90

During the sensitivity analysis, it was also found that the model was moderately sensitive to variations in the chloride value assigned to the domestic-direct recharge, and an increase or decrease of the estimated concentration by 50 percent resulted in about a 7-percent mean change for all sample sites. The importance of domestic-direct recharge as a mechanisms for chloride recharge is also seen when it is noted that the model is much more sensitive to this recharge mechanism than it is to the the geometric dispersivities.

Next, the sensitivity of the inodel to the assumed concentrations assigned to land-surface-applied recharge was analyzed. The chloride concentrations originally assigned to this recharge were varied by a multiplying factor that ranged from 0.0 to 2.0. This resulted in an overall change of less than 5 percent in the predicted chloride conceritration field (less than $0.1 \mathrm{mg} / \mathrm{L}$ average chloride change). This indicates that the model is relatively insensitive to variations in concentrations assigned to the land-surface-applied recharge for the Spokane aquifer. It was found that though the model is relatively insensitive to these variations of chloride flux from land-surface-applied water, the model-predicted chloride values matched the observed values better when the source was included. Also, it was found that an even better match was achieved when the model-computed chloride concentrations of water pumped for lawn watering and irrigation were uniformly increased upwards. Increasing the chloride probably represents additional source inputs resulting from fertilization, the build-up of dissolved salts temporarily residing in the unsaturated zone due to evapotranspiration, and other possible sources, such as road salting. Final values of these uniform chloride-concentration increases, which are added to the model-computed pumped-source water concentrations, were 0.5 $\mathrm{mg} / \mathrm{L}$ for the applied recharging water from lawn water and $0.1 \mathrm{mg} / \mathrm{L}$ from agricultural irrigation.

The model was found to be very sensitive to boundary conditions; varying the boundary concentrations by multiplying factors of 0.5 and 1.5 resulted in an overall change of about 28 percent in the predicted chloride concentration field. This indicates not only the importance for accurate boundary inflows in the model, but also the need for good chemical-constituent data at boundary-inflow locations. 


\section{Calibration Results}

Statistical measures relating how well the mass-transport model is calibrated are given in the table on page . These measures show that the model provides statistically acceptable results, and is capable of explaining more than 80 percent of the variance in the observed concentrations as measured by the r-squared value.

The overall percent error, based on comparing the mean of the observed averages with the predicted mean of the 138 values, is 14 percent. This overall error is believed to comprise errors in (in order of importance): (I) boundary conditions; (2) input loading concentrations; (3) model parameters; (4) flow-model results; and (5) conceptual and numerical models of flow and mass transport. A map of the calculated difference between average observed chloride-concentration values and predicted values at specific nodes closest to the observed data is shown in figure 23.

River chloride concentrations for both the Spokane and Little Spokane Rivers were also used in the time-averaged calibration. Table 4 shows average observed concentrations and discharges at four sites on the Spokane River and three sites on the Little Spokane River. Also shown are additional predicted concentrations at four sites on the Spokane River. The sites shown for both rivers are in downstream order.

The model-calculated chloride mass-flux budget for the time-averaged simulation shown in table 5 represents the average contributions of dissolved chloride from various sources to and from the Spokane aquifer, Spokane River, and Little Spokane River during the study period. The values in table 5 are average values and are subject to the model errors discussed previously.

The largest mass-flux component in the aquifer time-averaged budget is the mass inflow at the boundaries. The other principal sources of chloride to the aquifer, as determined during calibration, are domestic-direct recharge and, to a much smaller extent, lawn watering, industrial-applied water, and precipitation. Chloride is removed from the aquifer mainly through discharge to both the Spokane and Little Spokane Rivers and through pumping.

The Spokane River has a calculated chloride mass flux leaving the study area near Long Lake that is more than double the mass flux entering at the state line. The increase is estimated to be mainly from the City of Spokane sewage treatment plant, with additional inputs from aquifer leakage and Hangman Creek inflow. The increase in chloride mass flux in the Little Spokane River as it leaves the study area is due to discharge from the aquifer. 
TABLE 4.--Calculated and observed average annual river concentratiuns at selected river nodes for time-averaged caliuration simulation

\begin{tabular}{|c|c|c|c|c|c|c|c|c|}
\hline $\begin{array}{l}\text { Name } \\
\text { Spokane } \\
\text { River }\end{array}$ & $\begin{array}{c}\text { Post falls, } \\
\text { Idaho } \\
\text { gaging site }\end{array}$ & $\begin{array}{l}\text { Siate } \\
\text { line }\end{array}$ & $\begin{array}{l}\text { Green- } \\
\text { acres }\end{array}$ & $\begin{array}{l}\text { Pines } \\
\text { Road }\end{array}$ & $\begin{array}{l}\text { Argonne } \\
\text { Rodd }\end{array}$ & $\begin{array}{l}\text { Spokane } \\
\text { gage }\end{array}$ & $\begin{array}{l}\text { Seven } \\
\text { mile }\end{array}$ & $\begin{array}{l}\text { Nine } \\
\text { mile }\end{array}$ \\
\hline $\begin{array}{l}\text { Predicted chloride } \\
\text { value, in } \mathrm{mg} / \mathrm{L}\end{array}$ & 0.6 & 0.6 & 0.6 & 0.63 & 0.65 & 0.8 & 1.55 & 1.55 \\
\hline $\begin{array}{l}\text { Average observed } \\
\text { chloride value, } \\
\text { in my/L }\end{array}$ & -. & .6 & -. & .9 & .7 & -. & -. & 2.0 \\
\hline $\begin{array}{l}\text { Predicted river } \\
\text { discharge, in } \mathrm{ft}^{3} / \mathrm{s}\end{array}$ & 5,383 & 5,362 & 5,338 & 5,570 & 5,571 & 5,774 & 5,998 & 6,010 \\
\hline
\end{tabular}

\begin{tabular}{|c|c|c|c|c|}
\hline $\begin{array}{l}\text { Naine } \\
\text { Little } \\
\text { Spokane River }\end{array}$ & $\begin{array}{l}\text { Dattord, wanderm } \\
\text { Wash. }\end{array}$ & re Nine-mile & & \\
\hline $\begin{array}{l}\text { Predicted chloride } \\
\text { value, in } \mathrm{mg} / \mathrm{L}\end{array}$ & 1.7 & 2.53 & & \\
\hline $\begin{array}{l}\text { Average observed } \\
\text { chloride value, } \\
\text { in mg/L }\end{array}$ & 2.8 & 2.7 & & \\
\hline $\begin{array}{l}\text { Predicted river } \\
\text { discharge, in } \mathrm{ft}^{3} / \mathrm{s}\end{array}$ & 299 & 483 & & \\
\hline$=-1-1-2$ & $\begin{array}{l}\text { Predicted chloride } \\
\text { value, in mo/l. }\end{array}$ & $\begin{array}{l}\text { Average observed } \\
\text { chloride value, in } \mathrm{mg} / \mathrm{L}\end{array}$ & $\begin{array}{l}\text { Predicted river } \\
\text { discharge, in } \mathrm{ft}^{3} / \mathrm{s}\end{array}$ & 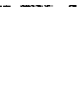 \\
\hline $\begin{array}{l}\text { NAME } \\
\text { Spokane River }\end{array}$ & . & & & \\
\hline $\begin{array}{l}\text { Post Falls, } 10, \\
\text { gaging station }\end{array}$ & 0.6 & -- & 5,383 & \\
\hline State line & 0.6 & .6 & 5,362 & \\
\hline Greenacres & 0.6 & -- & 5,338 & \\
\hline Pines Roait & 0.63 & .9 & 5,570 & \\
\hline Argunne Road & 0.65 & .7 & 5,571 & \\
\hline Spokane gage & 0.8 & -. & 5,774 & \\
\hline Sevenmile & 1.55 & -- & 5,998 & \\
\hline Ninemile & 1.55 & 2.0 & 6,010 & \\
\hline & $\begin{array}{l}\text { Predicted chloride } \\
\text { value, in } \mathrm{mg} / \mathrm{L}\end{array}$ & $\begin{array}{l}\text { Average observed } \\
\text { chloride value, in } \mathrm{mg} / \mathrm{L}\end{array}$ & $\begin{array}{l}\text { Predicted river } \\
\text { discharge, in } \mathrm{ft}^{3} / \mathrm{s}\end{array}$ & \\
\hline $\begin{array}{l}\text { Name } \\
\text { Little Spokane } \\
\text { River } \\
\end{array}$ & & & & \\
\hline Dartford, WA & 1.7 & -- & 2.53 & \\
\hline Wandermere & 2.75 & 2.8 & 3.14 & \\
\hline Ninemile & 2.53 & 2.7 & 483 & \\
\hline
\end{tabular}


TABLE 5.--Model-calculated chloride mass-flux budget for timeaveraged conditions, May 1977-May 1978. (Positive values are fluxes to the aquifer and(or) rivers; negative values are fluxes out of the aquifer and (or) rivers.)

Spokane aquifer

Chloride mass flux

$\left(\mathrm{ft}^{3} / \mathrm{s}-\mathrm{mg} / \mathrm{L}\right)$

Boundary inflow

1,209

Boundary outflow

$-170$

Applied water (land surface and subsurface)

Domestic

Lawn watering

1,000

Industrial

Irrigation

Leakage to Spokane River

Leakage to Little Spokane River

Pumpage

$-1,201$

$-836$

Precipitation

Total change

104

Spokane River

Boundary inflow

Boundary outflow

3,230

Leakage from aquifer

Hangman Creek

$-9,322$

1,201

723

Sewage treatment plant

3,978

Industrial

190

Total change

Little Spokane River

Boundary inflow

Boundary outflow

$-7,225$

Leakage from aquifer

Total change 


\section{Transient Model}

The mass-transport model was designed to calculate the concentration of a conservative coristituent, chloride ion for this study, as a function of time as well as space. A calibrated transient model can be used to estimate the spatial movement of selected pollutants introduced into the aquifer and(or) river, or predict the distribution of a conservative constituent in the aquifer, at any time.

Testing during transient calibration determines whether porosity and saturated thickness are defined sufficiently to predict the observed temporal changes in chloride concentrations. The above testing assumes that the initial and boundary conditions and the estimates of the temporal distribution of the concentrations assigned to inpurs are specified correctly. Thus, the only unknown parameters are the porosity and saturated thickness, which have been estimated and used in the fluid flow model calibration (Bolke and Vaccaro, 1981).

One transient model simulation was done for the study period, May 1977 to April 1978, utilizing a 10-day time step. This simulation used the flow parameters described in Bolke and Vaccaro (1981) for the fluid flow part of the model. Initial conditions were obtained from a time-averaged simulation for the month of May 1977. The boundary conditions for the mass-transport model used the mean of the observed boundary concentrations obtained from the three sampling periods. The mean values were then varied each month by multiplying them by a monthly factor (a distribution coefficient). The monthly factors represent the mean monthly variation of all the boundary concentrations from the mean boundary concentration. The concentrations assigned to the first river nodes of the Spokane and Little Spokane Rivers were specified as monthly averages and were based on observed and estimated data. All other input concentrations (for the sewage treatment plant and industrial effluents, septic tanks, and precipitation) were kept constant.

The predicted concentrations, at the points in time and space where observed data were available, were then compared with observed data from the three water-sample periods. The comparison consisted of: 1) computing of the statistical measures discussed in the previous section; 2) visual check of the predicted, observed, and residual chloride distribution in the ground-water system; and 3) a check on the match between the predicted and observed chloride concentrations in the Spokane River at selected locations from the May 1978 sample period. The computed statistics for the three water-sample periods are listed in table 6, and the observed ard predicted chloride concentrations at selected points along the Spokane River are shown in table 7.

The statistical measures in table 6 and the match between the observed and predicted chloride-values along the Spokane River in table 7 show that the transient model can reasonably reproduce the observed temporal variations in chloride concentrations. Also, the measures of the "goodness of fit" improve with time, indicating that the initial conditions were in error--they were not sufficiently defined. 
TABLE 6.--Statistics for transient mass-transport calibration

\begin{tabular}{|c|c|c|c|c|}
\hline Date & & Observed & Predicted & $\begin{array}{l}\text { Mean } \\
\text { residual }\end{array}$ \\
\hline $5 / 77$ & $\begin{array}{l}\text { Mean } \\
\text { Standard deviation } \\
\text { Number observed data } \\
r \text {-squared value }\end{array}$ & $\begin{array}{l}3.39 \\
3.97\end{array}$ & $\begin{array}{r}2.96 \\
2.66 \\
123 . \\
.460\end{array}$ & $\begin{array}{l}0.44 \\
3.04\end{array}$ \\
\hline $10 / 77$ & $\begin{array}{l}\text { Mean } \\
\text { Standard deviation } \\
\text { Numbered observed data } \\
r \text {-squared }\end{array}$ & $\begin{array}{l}3.58 \\
4.13\end{array}$ & $\begin{array}{c}3.09 \\
3.17 \\
113 . \\
.603\end{array}$ & $\begin{array}{r}.49 \\
2.03\end{array}$ \\
\hline $5 / 78$ & $\begin{array}{l}\text { Mean } \\
\text { Standard deviation } \\
\text { Number observed data } \\
r \text {-squared }\end{array}$ & $\begin{array}{l}3.65 \\
3.05\end{array}$ & $\begin{array}{r}2.97 \\
2.68 \\
118 . \\
.824\end{array}$ & $\begin{array}{r}.68 \\
1.73\end{array}$ \\
\hline
\end{tabular}


TABLE 7.--Calculated and observed chloride concentrations for the Spokane River, transient simulation

\begin{tabular}{lcc} 
Location & $\begin{array}{c}\text { Observed, } \\
5 / 7 / 78\end{array}$ & $\begin{array}{c}\text { Predicted, } \\
4 / 30 / 78\end{array}$ \\
\cline { 2 - 3 } State line & 0.6 & 0.6 \\
Harvard Road & .6 & .6 \\
Greenacres & .6 & .6 \\
Trent Bridge & .7 & .63 \\
Argonne Road & .7 & .63 \\
Mission Street & .7 & .67 \\
Trent Avenue & .8 & .67 \\
Spokane Bridge & .7 & .69 \\
Fort Wright Bridge & .7 & .71 \\
Riverside State Park & 1.2 & .97 \\
Seven-Mile Bridge & 1.2 & .98
\end{tabular}


Several aspects should also be noted concerning the transient simulation. The first is that an examination of the spatial distribution of the residuals (observed minus model predicted values) shows that the largest errors are located near boundaries. This indicates that either the monthly multiplying factor for boundary conditions or the specified mean boundary concentrations were not sufficiently defined. It was shown in the sensitivity analysis section that the boundary conditions are the most important input and that the system output is most sensitive to them. The mean of the observed chloride values at boundary inflow areas are estimated to be representative values; however, the monthly cyclic variation of this mean concentration was not able to be estimated very accurately and the lumping of the monthly factors (which account for the cyclic variations) as single monthly values were assumed to be the same for every boundary inflow area. Therefore, most of the error is attributable to the inaccuracies (due to the multiplying factors) and lack of chemical data at some boundary inflow areas.

Due to the lack of definitive time vary information at boundary inflow locations, the transient model can not be considered to be calibrated; at times model error near boundaries is larger than some observed temporal chloride variations. The observed temporal variations were small on an absolute scale $(0.5$ $\mathrm{mg} / \mathrm{L}$ ) but when the observed values at a single sample point are compared, it is noted that the relative variation is large, generally at least 20 percent. Thus, it would be erroneous to adjust the porosity vs saturated-thickness matrix to achieve a better match of the predicted chloride values with the observed data from the three sample periods because this assumes that most of the errors are in the model-calibrated parameters. Because of this and the desire to be able to use the transient mass-transport model at least qualitatively, a sensitivity analysis was done for the porosity vs saturated-thickness matrix. Assuming these values are known within relatively narrow limits (20 percent), the sensitivity analysis showed how sensitive the model-simulated output is to variations in these input parameters. Therefore, a mean percent error due to these parameters was assigned to the computed output, and is based on an acceptable range of the porosity vs saturated-thickness matrix.

Two transient-model simulations were done for the sensitivity analysis. The initial estimates of the porosity vs saturated-thickness matrix were varied by plus and minus 20 percent, and the resulting values were used as input for the transient simulations. The computed concentrations from the two simulations were then compared with computed concentrations from the transient calibration simulation using the initial estimates of porosity and saturated thickness. It was found that the change in sirnulated output was minor--a mean change of 1 percent for the computed chloride values, or, for the two simulations the mean ground-water chloride concentration changed from $2.54 \mathrm{mg} / \mathrm{L}$ to 2.57 , and $2.52 \mathrm{mg} / \mathrm{L}$. The mean and the standard deviation of the residuals for the 20 -percent increase simulation and the 20-percent decrease simulation were $0.02 \mathrm{mg} / \mathrm{L}, 0.05 \mathrm{mg} / \mathrm{L}$, and $-0.03 \mathrm{mg} / \mathrm{L}$ and $0.07 \mathrm{mg} / \mathrm{L}$, respectively. The three largest residuals in the simulations were $0.69,0.49$, and $0.31 \mathrm{mg} / \mathrm{L}$. The largest changes were in the boundary areas, where porosity and saturated thickness are most important. The average change in boundary areas was about 3 percent, which is less than the percentage difference between the observed and predicted values in the boundary areas. 
The sensivity analyses completed for the time-averaged and transient models showed the reasonableness and sensitivity of the input concentrations and parameters. Assigned concentrations for the effluent sources were derived from observed or literature-based data and tested through the sensitivity analyses, and the first river-node concentrations were based on observed data. Thus, the two inputs into the model that are not well defined are the boundary conditions and the porosity-saturated thickness matrix; however, the output sensitivity is known. The above and the results presented in tables 6 and 7 show that the transient-model formulation and implementation is reasonable. If the boundary conditions were defined better, the transient model could be calibrated, that is, model error would be reduced and the temporal variation in chloride concentrations could be matched with a smaller percent error.

Although the model is not adequately calibrated for transient conditions, qualitative interpretation of transient-model output such as size and movement of plumes, magnitude of mass fluxes of the system components, and movement of dissolved constituents between the rivers and the aquifer can be made. The movement of plumes can be interpreted qualitatively since the boundary concentrations would be zero, the main source of error in a transient analysis; however, the time step size should be chosen such that the concentration information desired would be computed over a spatial scale of the finite elements. This precludes the analysis of small (local) tracking over a sub-grid size where the spatial dependency. of the flow parameters and dispersivity would be different, which is the difference between a land-use impact oriented model and a model developed for studing a known or possible material point source.

In many instances, a qualitative analysis is sufficient for an engineering/management decision or to increase the knowledge of how chemical constituents move through the system. The usefulness of this type of analysis is shown by the predicted temporal variation in mass-flux components of the system. The total chloride mass-flux recharge and discharge for the Spokane aquifer for the study period is shown in figures 24 and 25 . In these figures the ordinate values have been normalized and each term divided by the smallest term to represent a relative order of magnitude. Though the predicted numerical value might not be correct, the order of magnitude of each budget item with respect to the others and to the temporal variation is thought to be reasonable.

An analysis of figures 24 and 25 shows the following cause-and-effect relationships: cyclic variations in pumping withdrawals, precipitation, and boundary mass fluxes are accounted for by cyclic variations in chloride fluxes to the Spokane River and the change in chloride stored in the aquifer. The change in chloride stored in the aquifer is the difference between recharge and discharge and is a function of the falling and rising water levels in the aquifer. The cyclic variations are not reflected in the discharge to the Little Spokane River or in discharges across the downstream outflow boundary. Therefore, a qualitative analysis of a transient simulation increases the knowledge of the movement of chloride through the system and can give order-of-magnitude estimates to questions that otherwise could not be approached in such a dynamic system with so many interacting components. 


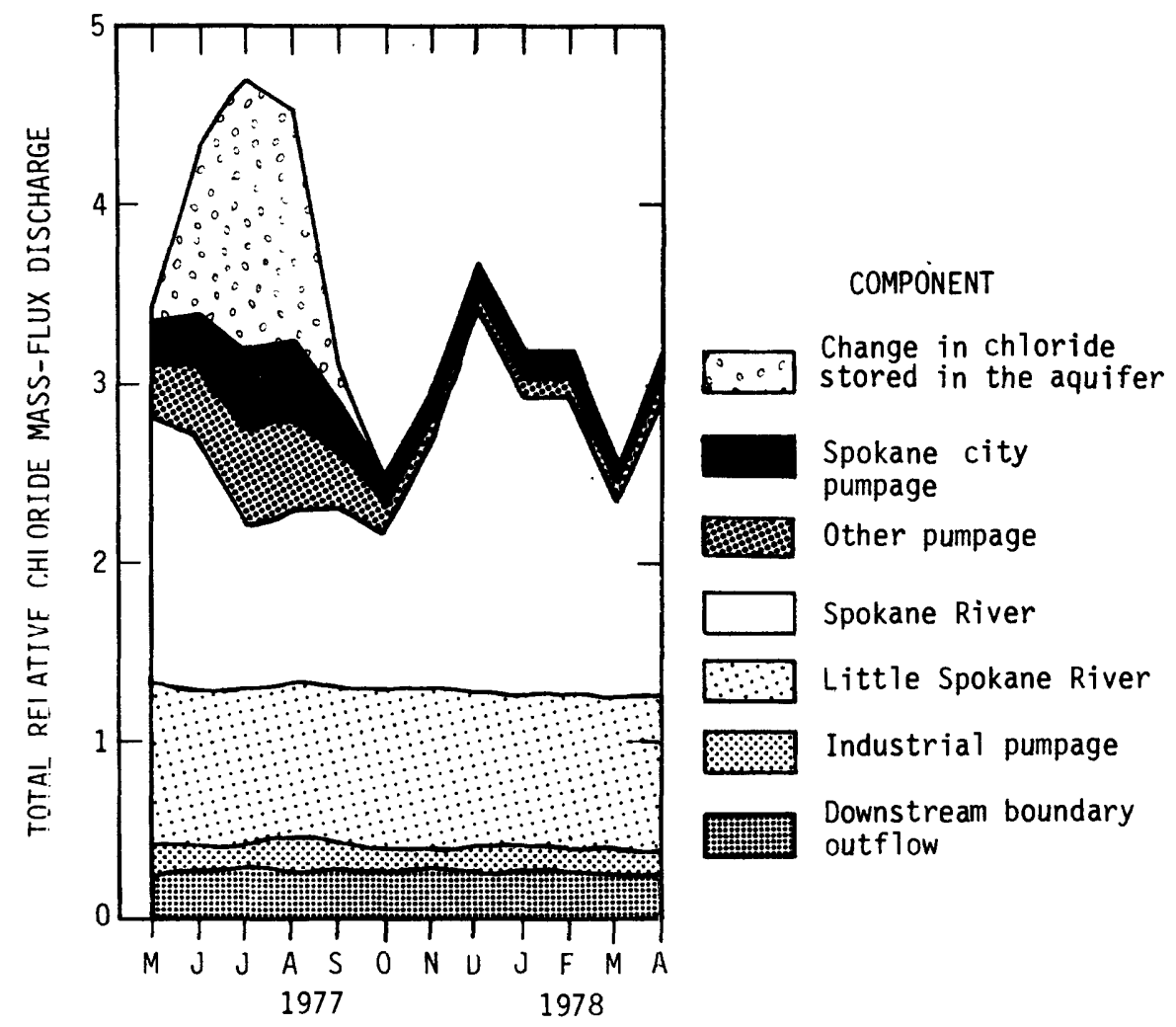

FIGURE 24.--Computed temporal variation in chloride mass-flux discharge. 


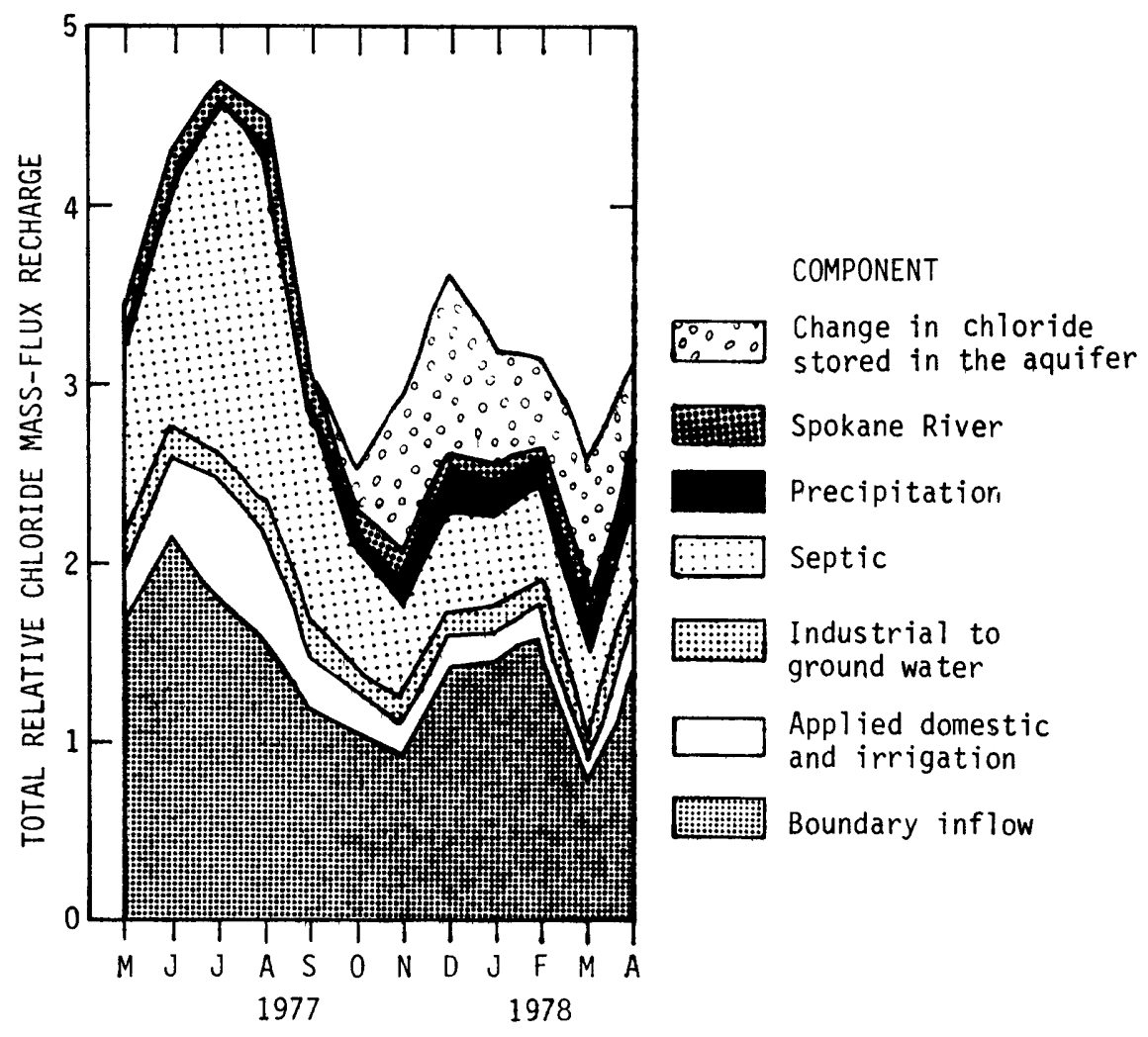

FIGURE 25.--Computed temporal varlation in chloride mass-flux recharge. 


\section{MODEL UTILIZATION}

The previous sections delineated the methodology used to calibrate the mass-transport model. The time-averaged calibration accepted was shown to be a statisically 'good-fit' model, based on the current available data. Two results of the calibration procedure and sensitivity analysis were: 1) the conceptual model of aquifer loadings was reasonable; and 2) for the time-averaged model an average percent error was established for predicted chloride concentrations.

The time-averaged model was used to estimate the impact of domestic-direct recharge and land-surface-applied recharge on the chloride concentration distribution in the Spokane Valley aquifer. A simulation was made in which these two chloride sources were removed from the model, while boundary fluxes were retained. The computed chloride values from this simulation were then subtracted from the chloride values obtained when these sources were included - the computed output of the calibrated model. This resulted in the residual chloride concentration distribution shown in figure 26 , which shows the predicted change in chloride concentration due to land-surface activities. The values shown in the figure represent the best estimate of the probable impact on the aquifer of domestic-direct recharge and land-surface-applied recharge. Note that the boundary concentrations assigned were obtained from averaged observed data. Therefore, the boundary concentrations might include effects of domestic-direct recharge, especially when the boundary is in an unsewered area of high population density. This would cause the relative chloride impact due to overlying land uses to be greater than that shown in figure 26. It is difficult to separate the actual concentration of boundary inflow from the concentration that might be associated with domestic-direct recharge. Figure 26 is a reasonable approximation of the impact of land usage on chloride concentrations in the aquifer because only six nodes are believed to be subject to this boundary inflow. Also, utilizing specified flux boundary conditions along the north and south boundaries allows for boundary concentrations to be computed, because the concentration assigned to the boundary water inflow is not necessarily the concentration that will be computed by the model. Therefore, if the computed concentrations at boundaries are higher than the observed concentrations, then the concentrations assigned to the inflow water are too high; if computed concentrations are lower, then assigned concentrations are low too. The use of specified flux boundary conditions lets the assigned boundary concentrations approach the true concentration of inflow water.

The contour map of residual concentrations shows that the impact of recharge from land usage on chloride distribution in the aquifer is small, generally less than 1 $\mathrm{mg} / \mathrm{L}$ throughout approximately 80 percent of the aquifer. Local areas of concentration increases that exceed $3 \mathrm{mg} / \mathrm{L}$ occur in peripheral areas near Opportunity, north of Irvin, and at the south boundary of the model in or near the city of Spokane.

The areas of residual concentrations in figure 26 closely match the observed areal variations in chloride. An example of this match is depicted by well 25/44-9P1, shown in figure 26. This well has an average annual concentration of about $1.7 \mathrm{mg} / \mathrm{L}$, which is about $0.7 \mathrm{mg} / \mathrm{L}$ higher than what is entering at the upstream model boundary. From figure 26, most of this increase can be attributed to the land-surface activities. 


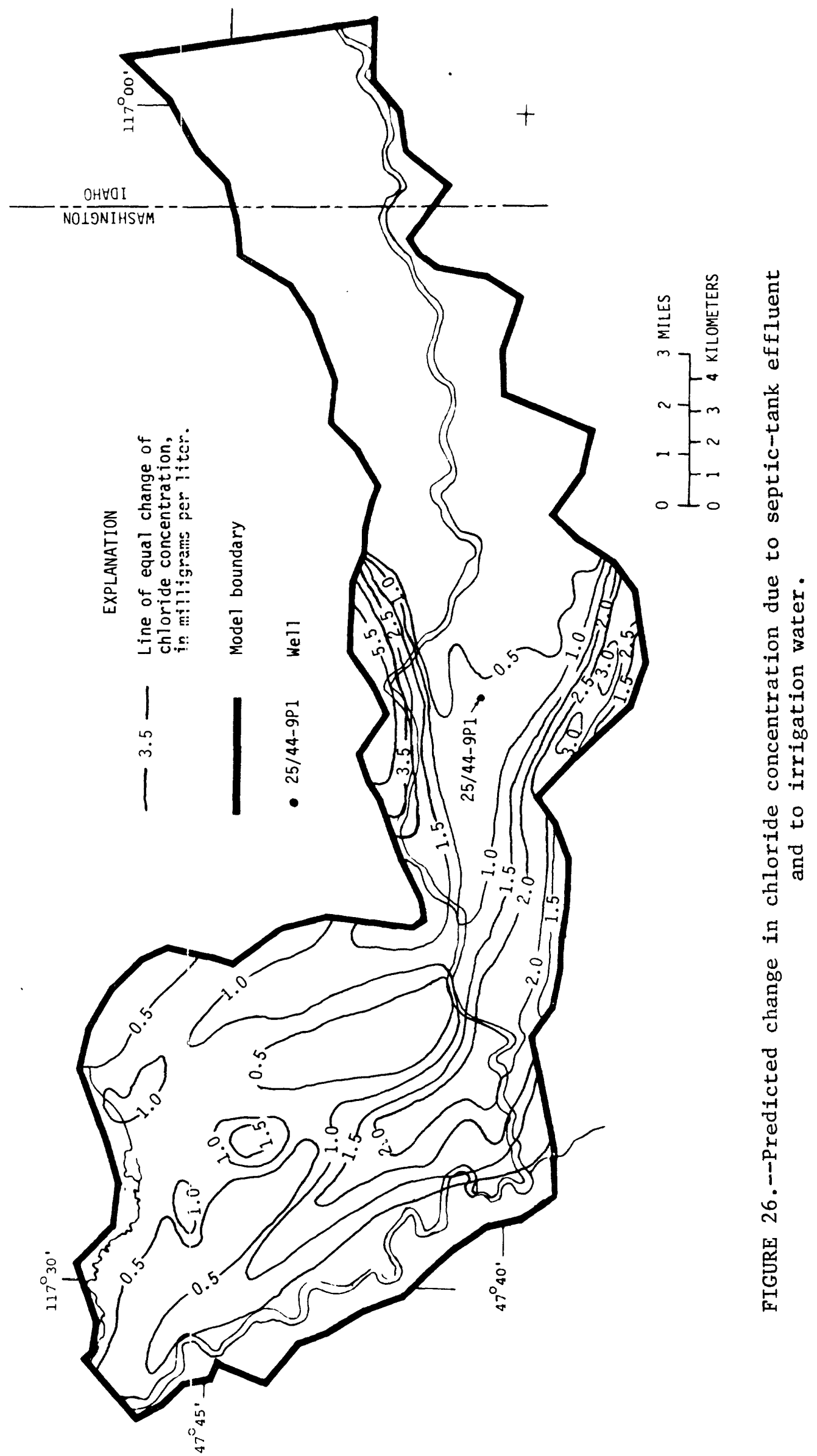


The predicted-chloride-change map shown in figure 26 exhibits a spatial distribution (shape) that does not correspond directly with the computed loadings, figure 8. The computed distribution is a function of the factors listed in the table below. The most important factors that produce the computed distribution are not readily apparent because of the complexity of the hydrological system. Therefore, a nonparametric Spearman correlation method (Conover, 1971, p. 245) was used to calculate correlation coefficients between the observed data and several physical parameters in order to give more insight into the dominant physical parameters.

\begin{tabular}{lc}
\hline Parameter & $\begin{array}{c}\text { Correlation } \\
\text { coefficient }\end{array}$ \\
\cline { 2 - 2 } Proximity to bounds & -0.4615 \\
Porosity & .47639 \\
Saturated thickness & -.37008 \\
Transmissivity & -.57879 \\
Vertically integrated velocity & -.43483 \\
Discharge per unit width & -.57341 \\
Man-induced loadings & .09130 \\
Saturated thickness x porosity & -.29059 \\
Land-use type & -.30669 \\
River influence & -.14846 \\
Non-dimensional loading & -.47572 \\
\hline
\end{tabular}

The parameters that were used in the analysis were: transmissivity (T), velocity $(v)$, porosity $(\theta)$, saturated thickness (b), discharge per unit width $(v / \theta b)$, saturated thickness times porosity, man-induced loadings (land-surface loadings, fig. 8), a nondimensional land-surface loading, proximity to boundaries, type of land use at observation point, and river influence. The last three characteristics were assigned numerical values according to: 1) how close an observation point was to a boundary; 2) the type of land use (urban/sewered, suburban/unsewered, industrial, agricultural, and suburban/agricultural); and 3) whether an observation point was located near an area where the river discharges to the aquifer. The nondimensional loading was obtained by multiplying man-induced loadings by the density of water (assumed constant) and dividing the resulting number by transmissivity, saturated thickness, and porosity.

The correlation analysis showed that the distribution is most closely correlated with transmissivity, discharge per unit width, and nondimensional loading (the surface loading that incorporates transmissivity).

The source of estimated loadings showed little correlation with the chloride distribution, but there was a higher correlation for nondimensional loading. The higher correlation coefficient for nondimensional loading helps to explain the increased concentrations in peripheral areas--loadings and aquifer parameters interact strongly. The velocity field (fig. 7) along the aquifer boundaries shows that the movement of chloride in these areas would not be directly into the main aquifer flow system. Transmissivity and specific discharge per unit width are lower 
along the aquifer boundaries. Transport direction, lower specific discharge per unit width, and high loadings contribute to increased chloride concentrations in the peripheral areas. Once the chloride is transported out of the peripheral areas, concentration immediately decreases due to dilution. An exception to this is chloride transported out of the Opportunity area. This water follows the south boundary, where the velocity and flow quantities are relatively low, and the result is a narrow band of increased chloride concentration of 2.0 to $2.5 \mathrm{mg} / \mathrm{L}$.

The experiment showed that the estimated impact of domestic-direct recharge and land-surface-applied water on chloride distribution is small, generally less than $1 \mathrm{mg} / \mathrm{L}$ over approximately 80 percent of the aquifer. This is because of the properties of the hydrologic system (high transmissivities and velocities, dilution of aquifer water from river losses, discharge of chloride from the aquifer to the Spokane River, and the good quality and large quantity of ground water in the system). Local areas of increased chloride concentration result from the interaction between high loadings and direction and magnitude of ground-water flow. 


\section{SUMMARY}

More than one-quarter of a million people live and work over the Spokane Valley aquifer. Water for their domestic, industrial, and agricultural needs is obtained solely from the Spokane aquifer. Water pumped from the aquifer is distributed and used for these activities. The water that is not consumptively used is returned to the ground-water reservoir. Land-use activities can have a deteriorating effect on water quality through the addition and concentration of materials dissolved in the "water." To assist in an assessment of the effect on land-use activities and as an aid in interpreting areal, temporal, and vertical water-quality data, a dissolved-chloride loading (recharge) map was computed. The heaviest loadings occur south of Opportunity and north of Irvin.

Areal representation of ambient water quality was accomplished by analyzing constituents easily correlated with water-chemistry variations that might indicate recharge from a particular land use. Specific conductance was observed to range from 73 to 820 micromhos, chloride ranged from 0.4 to $24 \mathrm{mg} / \mathrm{L}$, and nitrate-nitrogen from 0 to $8.8 \mathrm{mg} / \mathrm{L}$.

Specific conductance was compared with the major dissolved chemical constituents and was found to correlate well with dissolved solids, hardness, calcium, bicarbonate, and magnesium. A less reliable correlation with specific conductance was noted with chloride and sodium. Nitrate-nitrogen showed a poor correlation with specific conductance.

Average specific conductance, chloride, and nitrate- $\mathbf{N}$ areal distributions for the periods May 1977, October 1977, and May 1978 indicated lower values of these characteristics down through the central part of the valley and higher values in the peripheral areas. Eighty percent of the observed specific-conductance values ranged from 200-400 micromhos; 85 percent of the nitrate- $\mathrm{N}$ values ranged from 0.0-3.0 $\mathrm{mg} / \mathrm{L}$, showing the consistent quality of the aquifer. Historical data show that short-term variations in specific conductance are generally greater than any long-term variations yet observed.

Vertical changes in water chemistry in the upper 50 feet of the aquifer were examined in a series of wells drilled along several sections across the valley. Interpretation of the data from these cross-section wells is useful only on a per-well basis, and vertical and temporal variations cannot be correlated areally over the aquifer.

Vertical concentration gradients of water chemistry were observed in four wells. The vertical difference is attributable to high values of surface loading, proximity to boundaries with high concentration fluxes into the aquifer, periodic local mixing of water derived from the river with native ground water, and a rising water table intercepting downward-migrating water and (or) salts in storage in the unsaturated zone. 
A numerical mass-transport model for conservative chemical constituents was developed and coupled with an existing fluid-flow model of the aquifer system. The partial differential equation describing mass transport was solved by the Galerkin-finite element method. The numerical model can simulate the areal distribution of a conservative chemical species if the boundary conditions and stresses are sufficiently defined. The model also computes the species concentration in the water of the Spokane and Little Spokane Rivers and a mass-flux budget of the chemical sources and sinks to the aquifer system.

The mass-transport model was calibrated for the time-averaged conditions using chloride as the conservative chemical species. The time-averaged model was calibrated by using observed or estimated chloride concentrations for the chloride sources to the aquifer and adjusting the longitudinal dispersivity until an acceptable match was obtained between simulated and observed chloride values. The observed chloride concentrations were measured in the aquifer during three sampling periods over a 1-year period. All fluid flow inputs were the annual averages for the study period. The calibration simulation was statistically acceptable and produced physically reasonable chloride concentration values in the aquifer and the rivers. A sensitivity analysis showed that it was reasonable to include domestic-direct recharge as a source of chloride. The model was not calibrated for transient conditions due to the lack of adequate observed temporal variations in chloride concentrations. However, porosity-saturated thicknesses are known within relatively narrow limits and are the only parameters that would be modified in the transient calibration. A sensitivity analysis completed on those parameters showed that within the estimated range of the parameters the simulated concentrations would vary less than 3 percent. Therefore, transient analyses may be interpreted at least qualitatively with a fair amount of confidence, with model error mainly resulting from the dominant boundary mass fluxes.

The model was used to estimate the impact of recharge from septic tanks and irrigation water on the Spokane aquifer using chloride as the indicator species. It was shown that there was less than $1 \mathrm{mg} / \mathrm{L}$ of change over approximately 80 percent of the aquifer as a result of these source loadings. There was a greater impact, averaging about $3 \mathrm{mg} / \mathrm{L}$, in the peripheral locations near Opportunity, north of Irvin, and in the south side of the modeled region in or near the city of Spokane.

Management decisions that can affect water quality can be evaluated with the model. Evaluations could be done with the time-averaged model. However, if a transient analysis is done the results should only be interpreted qualitatively. 


\section{REFERENCES}

Bear, J., 1972, Dynamics of fluids in porous media: New York, American Elsevier Publishing Company, Inc., 764 p.

Bolke, E. L., and Vaccaro, J. J., 1979, Selected hydrologic data for Spokane Valley, Spokane, Washington, 1977-1978: 0.S. Geological Survey Water Resources Investigations Open-File Report 79-333, 98 p.

Bolke, E. I., and Vaccaro, J. J., 1981, Digital-model simulation of the hydrologic flow system, with emphasis on ground water, in Spokane Valley, Washington and Idaho: U.S. Geological Survey Water-Resources Investigations Open-File Report 80-1300, 43 p.

Cherry, J. A., Gillham, R. W., and Pickens, J. F., 1975, Contaminant hydrogeology, 1. Physical processes: Journal Geoscience Canada 2(2), p. 76-84.

Collins, พ. D., and Williams, R. T., 1933, Chloride and sulfate in rainwater: Industrial Engineering Chemistry, v. 25, 944 p.

Conover, พ. J., 1971, Practical nonparametric statistics: New York, John Wiley \& Sons, 461 p.

Drost, B. W., and Seitz, H. R., 1978, Spokane Valley-Rathdrum Prairie aquifer, Washington and Idaho: O.S. Geological Survey Open-File Report 77-829, 79 p.

Duguid, J. O., and Reeves, M., 1976, Material transport through porous media: a finite-element Galerkin model: Oak Ridge National Laboratory, Environmental Sciences Division Publication 733, 198 p.

Eriksson, E., 1952, Composition of atmospheric precipitation', No. I and II: Tellus v. 4, p. 215-239; p. 280-303.

Esvelt and Saxton Consulting Engineers, 1964, Public health relationship of the Minnihaha sewer district to the Greater Spokane Community: Spokane, Washington, 33 p.

Finlayson, B. A., 1972, The method of weighted residuals and variational principles: New York, Academic Press, 412 p.

Griggs, A. B., 1966, Reconnaissance geologic map of the west half of the Spokane quadrangle, Washington and Idaho: O.S. Geological Survey Miscellaneous Geological Investigations Map I-464.

Hutchinson, G.E., 1957, A treatise on 1imnology: New York, John Wiley, v. 1, ch. 8,541 p. 
Hutton, S., and Anderson, D., 1971, Finite element method: a Galerkin approach: American Society Civil Engineers Proceedings, Journal Engineering Mechanics Division, A.S.C.E., 96:5, p. 1503-1519.

Johnson, A. I., 1966, Specific yield compilation of specific yields for various materials: U.S. Geological survey Open-File Report, Hydrologic Laboratory, Denver, Colorado, 119 p.

Kleiber, P., Whitfield, P. H., and Erlebach, พ. E., 1978, Limitations of single water samples in representing mean water quality: Canadian Department of Environment Inland Waters Directorate, Water Quality Branch Technical Bulletin No. 107, 30 p.

Lohman, S. พ., 1972, Ground-water hydraulics: U. S. Geological Survey Professional Paper 708, 70 p.

Mundorff, M. J., Bennett, G. D., and Ahmod, Masood, 1972, Electric analog studies of flow to wells in the Punjab aquifer of West Pakistan: U.S. Geological Survey Water-Supply Paper 1608-N, 28 p.

Smith, I. M., Farraday, R. V., and O'Connor, B. A., 1973, Rayleigh-Ritz and Galerkin finite elements for diffusion-convectional problems: Water Resources Research, v. 9, no. 3, p. 593-606.

Thomas, C. A., 1963, Investigation of the inflow to the Rathdrum PrairieSpokane valley aquifer: U. S. Geological survey unpublished report, 46 p.

Tracy, J. V., 1980a, Finite-element model for simulation of river-aquifer interchange: U.S. Geological Survey Open-File Report (in preparation).

---1980b, Documentation of a finite-element solute transport model: U.S. Geologic:al Survey Open-File Report (in preparation). '

Utah State University Foundation, 1969, Characteristics of pollution problems of irrigation return flow: Federal Water Pollution Control Administration, Robert S. Rern Water Research Center, Ada, Oklahoma, 237 p.

U.S. Army Corps of Engineers, 1976, Metropolitan Spokane Region water resources study: Appendix D, Wastewater generation and treatment, 466 p.

U.S. Environmental Protection Agency, 1976, Quality critera for water: Washington, D.C., 256 p.

Viraraghavan, N., and Warnock, R. G., 1976, Ground-water pollution from a septic tile field: Water, Air, and Soil Pollution, v. 5, p. 281-287. 